Hispania Sacra, LX

122, julio-diciembre 2008, 703-733, ISSN: 0018-215-X

\title{
LOS NOMBRAMIENTOS EPISCOPALES PARA LA CORONA DE CASTILLA BAJO FELIPE III, SEGÚN EL ARCHIVO HISTÓRICO NACIONAL: UNA APROXIMACIÓN
}

POR

BEATRIZ COMELla GUTIÉRREZ

Doctora en Historia (Universidad de Alcalá)

\section{RESUMEN}

La documentación del AHN revela que, de un total de 107 obispos elegidos por Felipe III para la Corona de Castilla, 67 fueron designados previa terna propuesta por la Cámara de Castilla y que, en el 30\% de los casos, el rey desoyó las sugerencias de sus colaboradores designando a otro candidato. Los nuevos obispos procedían mayoritariamente del entorno de la Corte, la Inquisición y las Órdenes religiosas, pero sólo se conoce el currículum de estudios de la mitad de ellos. De momento no es posible probar documentalmente la influencia de los confesores reales en los nombramientos episcopales.

PAlabras ClaVE: Nombramientos episcopales, Felipe III, Cámara de Castilla, Archivo. Histórico Nacional.

\section{THE EPISCOPAL APPOINTMENTS FOR THE CROWN OF CASTILE UNDER PHILIP III, ACCORDING TO THE HISTORICAL NATIONAL FILE: AN APPROACH}

\begin{abstract}
The documentation of the Historical National Archive reveals that among 107 of the Bishops elected by Philip the III for the Castillian Crown, 67 were previously designated as short list of the Castillian Chamber and, in 30\% of the cases, the King took no notice of suggestions and chose other candidates. The new bishops proceeded mainly from the Court, the Inquisition and the Religious Orders, but only the studies background of half of them are known. For the time being, it is not possible to prove by documents the influence Royal Confessors had in relation to appointment of Bishops.
\end{abstract}


KEY WORDS: Episcopal appointments, Philip the III, Castillian Chamber, Historical National Archive.

Recibido/Received 13-06- 2207

Aceptado/Accepted 06-09-2007

En el Archivo Histórico Nacional existe una amplia documentación inédita sobre el ejercicio del Patronato regio por la Monarquía hispánica, reseñada por Concepción de la Fuente y Esperanza Adrados Villar ${ }^{1}$. En este trabajo realizamos una aproximación a los nombramientos episcopales durante el reinado de Felipe III (1598-1621) ${ }^{2}$. El punto de partida ha sido una sugerencia del padre Quintín Aldea, Bibliotecario de la Real Academia de la Historia y se ha desarrollado bajo la dirección de Enrique García Hernán. Teniendo en cuenta lo publicado $^{3}$, nos acercaremos al nombramiento de los obispos ${ }^{4}$. Utilizaremos como fuente principal los Libros de Iglesia, que recogen la actividad de la Cámara de

1 Vid. C. DE la Fuente Cobos-E. Adrados Villar, «La documentación sobre el Patronato eclesiástico de Castilla» Hispania Sacra 47 (1995) 625-679. Se conservan 286 volúmenes de la Sección Consejos Suprimidos, que abarcan desde 1556 a 1834 y 2591 legajos comprendidos entre los años 1488 y 1848 archivados por diócesis; entre los libros hay 124 de la Secretaría de Real Patronato denominados Libros de Iglesia. Los fondos sobre el Patronato eclesiástico en la Corona de Aragón han sido estudiados por $\mathrm{M}^{\mathrm{a}}$ Jesús Álvarez-Coca.

2 Se trata de un reinado interesante por ser posterior al Concilio de Trento (1545-1563) y su duración no excesivamente larga permite, sin embargo, sacar conclusiones. Sobre Felipe III Vid. el clásico estudio de Ciríaco Pérez Bustamante, Felipe III. Semblanza de un monarca y perfiles de una privanza, Madrid, 1950; y otros más recientes como los de Paul C. Allen, Felipe III y la pax hispánica 15981621, Madrid, 2001 y Manuel LACARTA, Felipe III , Madrid, 2003.

${ }^{3}$ Q. AldEA sobre esta cuestión: «La Iglesia y el Estado en la España del siglo XVII», Miscelánea Comillas 36 (1961) 143-540; Política y religión en los albores de la Edad Moderna, RAH, Madrid, 1999 y El Cardenal Infante Don Fernando o la formación de un Príncipe de España, Madrid, 1999. También hemos contado con la aportación realizada por J.OlARRA y M. L. LARRAMENDI, Correspondencia entre la Nunciatura en España y la Santa Sede. Reinado de Felipe III, 7 vols., Roma, 1962-1967 y con las decisivas conclusiones en este ámbito de Maximiliano BARRIO GOZALO, «Perfil socio-económico de una elite de poder: los obispos de Castilla la Vieja 1600-1840» Anthologica Annua 28-29 (1981-1982) 71-138 y «Perfil socio-económico de una elite de poder: los obispos de Castilla y León 1600-1840» Anthologica Annua 30-31 (1983-1984) 209-291; Emilio CALLADo Estela, Iglesia, poder y sociedad en el siglo XVII: el arzobispo de Valencia Fray Isidoro de Aliaga, Biblioteca Valenciana, Valencia, 2001. Además ha resultado de interés la consulta de estudios sobre el Patronato regio durante el reinado de Felipe II como: Ángel FernándeZ COLlado, Gregorio XIII y Felipe II en la nunciatura de Felipe Sega (1577-1581). Aspectos político, jurisdiccional y de reforma. Estudio Teológico de San Ildefonso, Toledo, 1991 y las aportaciones de Ignacio FERnÁNDEZ TERRICABRAS, Por una geografía del patronazgo real: teólogos y juristas en las presentaciones de Felipe II, en E. MARTínEZ RUIZ - V. SUÁREZ Grimón, (Eds.) Iglesia y sociedad en el Antiguo Régimen, Las Palmas, 1994; Felipe II y el clero secular: la aplicación del Concilio de Trento y Conflictos entre Carlos $V$ y los cabildos catedralicios de la Corona de Castilla, ambos publicados por la Sociedad Estatal Centenario Carlos V y Felipe II, en 2000 y 2001 respectivamente.

4 Sobre esta cuestión, Vid. Matías Gómez Zamora, Regio patronato español e indiano, Madrid, 1897; Julián PAz EsPeso, Patronato real (1834-1851), 2 vols. Valladolid, 1946-1949; Quintín ALdEA, Q. Patronato real en España en Q. AldEA-T.Marín-J.Vives,(dir.) Diccionario de Historia eclesiástica

Hispania Sacra, LX

122, julio-diciembre 2008, 703-733, ISSN: 0018-215-X 
Castilla en materia eclesiástica ${ }^{5}$. También se analizará, paralelamente, la correspondencia de la Nunciatura de la Santa Sede en España durante estos años ${ }^{6}$.

Felipe III mantuvo embajada permanente en Roma. Entre 1598 y 1603 le representó el Duque de Sessa; a partir de agosto ese año y durante 1604 le sucedió el Duque de Escalona, reemplazado durante algunos meses por el Duque de Monteleón. Desde mayo de 1605, el Marqués de Falces se hizo cargo de la legación diplomática hasta septiembre de 1606 en que le sustituyó el Marqués de Aytona. Este se mantuvo en el cargo hasta el verano de 1609 en que asumió la embajada en Duque de Taurisano, que permaneció hasta mayo de 1616; entonces se encargó de la embajada el Cardenal Gaspar de Borja, hasta abril de 1619, que pasó a manos del Duque de Alburquerque ${ }^{7}$. Al principio del reinado, el embajador en Roma recibió de Madrid una relación de los negocios pendientes de resolución en la corte romana ${ }^{8}$.

Otra persona relacionada con los nombramientos eclesiásticos fue el Secretario de Patronato eclesiástico de la Cámara de Castilla. Entre 1598 y 1614 ostentó ese cargo Francisco González de Heredia; ocupado posteriormente por Tomás de Angulo, que se alternaba en dicha tarea con Jorge de Tovar y Valderrama, que le reemplazó definitivamente en $1615^{9}$. Según consta en la documentación consultada, fueron además miembros del Consejo de la Cámara de Castilla los siguientes:

- en 1599 los licenciados Guardiola, Acuña y el doctor Alonso Pérez de Ágreda en lugar de Juan de Valladares Sarmiento ${ }^{10}$.

de España, 5 vols. Madrid, 1975, vol. III, pp. 1944-1948 y 1948-1949 respectivamente. También Vid. Quintín AlDEA «La Iglesia y el Estado en la España del siglo XVII», Miscelánea Comillas 36 (1961) 143-540; Christian Hermann, L' Eglise d'Espagne sous le patronage royal (1476-1834): essai d'ecclesiologie politique, Madrid, 1988; Maximiliano BARRIo GoZALO, El real patronato y los obispos españoles del Antiguo Régimen 1556-1834, Madrid, 2004.

${ }^{5}$ Los libros correspondientes al reinado de Felipe III son AHN Consejos Libros 4-13. En ellos, además de los nombramientos eclesiásticos, se recogen los pleitos relacionados con los mismos, determinados eventos eclesiales (por ejemplo, canonizaciones), peticiones de copias de documentos al Archivo de Simancas, solicitud de compulsa de documentos, actas fundacionales eclesiásticas, nombramientos para Universidades, peticiones de plaza para el Colegio de Doncellas de Toledo, etc. Sobre la Cámara de Castilla. John ElLIOTT, La España imperial 1469-1719, Barcelona, 1965, p. 184. Sobre los obispos de Castilla y León: Maximiliano BARRIo GoZALO «Perfil socio-económico de una elite de poder: los obispos de Castilla la Vieja 1600-1840» Anthologica Аппиа 28-19 (1981-1982) 71-138 у «Perfil socio-económico de una elite de poder: los obispos de León 1600-1840» Anthologica Аnпиа 30-31 (1983-1984) 209-291.

${ }^{6}$ Vid. J. Olarra-M. L. Larramendi, Correspondencia entre la Nunciatura en España y la Santa Sede. Reinado de Felipe III, 7 vols., Roma, 1962-1967.

7 Vid. AHN Consejos Libros 4-13.

${ }^{8}$ En carta al Duque de Escalona fechada el 17-10-1605 se citan 24 asuntos pendientes. Cfr. Por ejemplo, AHN Consejos Libro 6 fol. 337v. Otra amplia relación de agosto de 1606 aparece en Consejos Libro 6 fols. 421 ss.

${ }^{9}$ Falleció el 25 de marzo de 1614 según consta en AHN Consejos Libro 9 fol. 330v.

${ }^{10}$ Cfr. AGS. Quitaciones de Corte, Leg. 6-392. 
- en 1603 el licenciado Fernando Carrillo ${ }^{11}$.

- en 1606 los licenciados Bohórquez y Alonso de Benavides.

- en 1614 el licenciado Gil Ramírez de Arellano ${ }^{12}$.

- en 1615 los licenciados Diego López de Ayala, Diego Aldrete de Haro, Melchor de Molina y Luis de Salcedo ${ }^{13}$.

La extensión del Patronato regio en la Corona de Castilla aparece claramente reflejada en la documentación. En febrero de 1603, el rey podía afirmar: «El licenciado Gil Ramírez de Arellano fiscal de mi Consejo me ha hecho relación que los sumos pontífices Adriano VI, Clemente VII y Paulo III, concedieron al emperador y a los reyes sus sucesores amplísima facultad y derecho de patronazgo para presentar a todos los obispados, arzobispados y abadías consistoriales de mis reinos como si realmente las hubieran fundado y dotado de su propio patrimonio» ${ }^{14}$.

En principio, los derechos reales se extendían a las iglesias, monasterios, dignidades, abadías, prioratos, prelacías y otras prebendas consistoriales que vacaren y tuvieran una renta superior a doscientos florines anuales ${ }^{15}$. Sin contar los beneficios curados y otros de rango menor, Felipe III ejerció el derecho de patronato en la Corona de Castilla sobre:

Arzobispados: Sevilla, Toledo, Santiago de Compostela, Burgos, Granada, Córdoba, Palencia, Osma, Valladolid, Zaragoza.

Obispados: Plasencia, Sigüenza, Cuenca, Salamanca, Pamplona, Zamora, Segovia, Ávila, Calahorra-La Calzada, León, Astorga, Coria, Cartagena, Badajoz, Cádiz, Ciudad Rodrigo, Oviedo, Tuy, Lugo, Orense, Mondoñedo, Guadix, Almería, Canarias, Málaga, Jaén.

Capillas reales: Reyes nuevos de Toledo, Reina Doña Catalina de Toledo, Reyes Viejos de Toledo, Real de Granada, Real de Sevilla, Real de San Marcos de Salamanca.

Abadías o Iglesias Colegiales consistoriales: Santander, Santillana, Covarrubias, Alcalá la Real, Sar, Arbás, Covadonga, Burgohondo, Medina del Campo, Alfaro, Roncesvalles, San Hipólito de Córdoba, San Miguel de la Escalada, San Clodio de Rivas de Sil, Santa Marina de Aguas Santas.

Prioratos: San Marcos de León, Santiago, Calatrava, Alcántara y Uclés ${ }^{16}$.

11 Vid. AGS. Quitaciones de Corte, Leg. 14-728-744.

12 Vid. AGS. Quitaciones de Corte, Leg. 21-1220-1231.

13 Vid. AHN Legajos 15198, II, 6 (2); 15206, II, 3 y 15213, II, 10.

${ }^{14}$ Cfr. AHN Consejos Libro 5 fol. 286.

${ }^{15}$ Cfr. AHN Consejos Libro 9 fol. 294. Al menos así era en teoría, pero de hecho, el monarca tuvo también derechos sobre rentas de menor cuantía.

${ }^{16}$ Vid. AHN Consejos Libros 4 y 5 passim. 


\section{LOS NOMBRAMIENTOS EPISCOPALES}

La designación de prelados diocesanos constituyó parte esencial del ejercicio del Patronato regio por la Casa de Austria ${ }^{17}$. El cuidado en la selección de obispos fue una constante durante todos los reinados.

Los criterios de selección para cubrir las vacantes de los obispados durante el reinado de los Reyes Católicos fueron las siguientes: ser naturales de estos reinos, honestos y letrados.

En 1571 se creó la Secretaría del Patronato real dentro de la Cámara de Castilla; su primer secretario fue Martín de Gaztelu. Le sucedió en el cargo Mateo Vázquez ${ }^{18}$. Felipe II señaló las condiciones para los candidatos al episcopado en su Instrucción de $1588^{19}$. Repetían los criterios de selección de sus predecesores añadiendo algunas notas nuevas. Los prelados debían ser: naturales de estos reinos, honestos, letrados, ordenados in sacris, limpios de sangre e hijos legítimos. Esta última condición se dispensó con mucha frecuencia ${ }^{20}$. El rey exigía candidatos virtuosos, cultos y competentes, de acuerdo con su entorno familiar y su clientela; también se tenía en cuenta los méritos propios del seleccionado ${ }^{21}$.

Desde Felipe II se tiende a considerar a los obispos como funcionarios públicos a los que se premia los servicios prestados con el traslado a diócesis más ricas. La carrera episcopal fue un auténtico cursus honorum en el que se ocupaban cargos eclesiásticos y civiles cada vez más importantes ${ }^{22}$.

La carrera episcopal solía tener estos pasos: el candidato del clero secular, ordinariamente había estudiado gramática en su villa o ciudad natal y pasaba después a la Universidad, donde acostumbraba obtener una beca en algún Colegio Mayor. Al finalizar sus estudios en teología o leyes, optaba a alguna prebenda catedralicia o puesto de la burocracia civil. Los candidatos del clero regular eran normalmente maestros en su respectiva orden y, con frecuencia, habían colaborado en el gobierno de sus comunidades religiosas ${ }^{23}$.

\footnotetext{
${ }_{17}$ Sobre los nombramientos eclesiásticos por la Casa de Austria, F. CosandeY-I. POUTRIN. Monarchies espagnole et française (1550-1714), París, 2001, pp. 437-439.

18 Vid. Ibidem pp. 64-97. Sobre la organización del gobierno de la monarquía española bajo los Habsburgo, Vid. F. COSANDEY-I. POUTRIN. Monarchies espagnole et française, o.c. pp. 309-330.

${ }^{19}$ Sobre ella Vid. Enrique García Hernán, «La Curia romana, Felipe II y Sixto V», Hispania Sacra 46 (1994) 631-649.

${ }^{20}$ Maximiliano Barrio Gozalo, El Real Patronato y los obispos españoles del Antiguo Régimen (1556-1834), o.c. pp. 143-144.

${ }^{21}$ Ibidem. pp. 51-52.

${ }^{22}$ Ibidem pp. 10 y 16 Sobre el currículum de los obispos designados por Felipe II Vid. Ignacio FerNÁNDEZ TERRICABRAS, Por una geografía del patronazgo real: teólogos y juristas en las presentaciones de Felipe II, en E. Martínez RuIZ.-V. SuÁrez Grimón (EDS.) Iglesia y sociedad en el Antiguo Régimen, Las Palmas, 1994, pp. 601-610.

${ }^{23}$ Maximiliano BarRIo Gozalo, El Real Patronato o.c. p. 78.
} 
La sucesión de un obispo tenía estas etapas: al morir un prelado, se informaba a la Cámara de Castilla sobre el valor de la mitra, pensiones que gravaban sus rentas y posibles candidatos. Para seleccionar a los designados, ordinariamente el rey se ajustaba al dictamen de la Cámara de Castilla, eligiendo a uno de los propuestos según la Instrucción de 1588. En alguna ocasión prescindió de los señalados por propia iniciativa o por influencia de su confesor, especialmente desde el reinado de Felipe III ${ }^{24}$. Fue costumbre de los monarcas hasta el reinado de Carlos III25. También el rey podía conseguir información sobre los candidatos elegibles a través de los prelados diocesanos a quienes periódicamente solicitaba una relación de personas «seguras, de celo, ciencia y conciencia» ${ }^{26}$. Se dio también la designación directa por el rey, sin consulta previa a la Cámara de Castilla, pero en menos del 10\% de los $\operatorname{casos}^{27}$.

Felipe III recibió de su padre unas directrices nítidas para designar obispos: convenía que fueran clérigos naturales de estos reinos ${ }^{28}$; honestos en el sentido de continentes y dedicados a sus tareas pastorales; de clase media o incluso pobres, para poner fin a la idea de ambicionar el episcopado como reducto trasnochado del feudalismo y, además, letrados, es decir, procedentes de algunos de los colegios universitarios ${ }^{29}$. Felipe III, se siguió el trámite habitual, propuesta previa de la Cámara de Castilla, en 67 de los 107 nombramientos.

Para las vacantes sobre las que podía ejercer su derecho de patronato, el rey solicitaba nombres de posibles candidatos. En julio de 1608 Felipe III escribía una carta circular a todos los obispos y cabildos de la Corona de Castilla con la siguiente amonestación:

\begin{abstract}
«Os ruego y os encargo muy afectuosamente por lo mucho que importa al servicio del nuestro Señor y de su Iglesia tengáys la mano y os abstengáys en todas las ocasiones que se ofrecieren de no dar en quanto sea posible aprobaciones particulares ni generales para que se pasen las prebendas de essa sancta Iglesia (...) sino fuere en personas en quien conocida y evidentemente se sepa y entendais concurren las partes y calidades de virtud, edad y letras y las demás que está dispuesto por el dicho sancto concilio» ${ }^{30}$.
\end{abstract}

El rey procuraba adelantarse y elegir a sus candidatos para las plazas vacantes. Recurría a la estrecha colaboración de los prelados y canónigos. En 1601,

\footnotetext{
${ }^{24}$ Ibidem pp. 69 y 72. Parece que con cierta frecuencia se elegía un candidato señalado por el confesor regio para la diócesis que resultaba vacante por el traslado de su prelado a otra sede, pp. 70-74.

${ }^{25}$ Maximiliano Barrio Gozalo, Los obispos de Castilla y León durante el Antiguo Régimen, Valladolid, 2000, pp. 32-33

${ }^{26}$ Maximiliano BARRIo Gozalo, El Real Patronato,o.c. p. 55.

${ }^{27}$ Ibidem p. 69.

${ }^{28}$ Cfr. AHN Consejos Libro 4 fols. 411-411v y Libro 5 fols. 109v-110. p. 220.

29 Ángel Fernández Collado, Gregorio XIII y Felipe II en la Nunciatura de Felipe Sega, o.c.

${ }^{30} \mathrm{Cfr}$. AHN Consejos Libro 7 fols. 153-154v.

Hispania Sacra, LX

122, julio-diciembre 2008, 703-733, ISSN: 0018-215-X
} 
Felipe III escribió al Cardenal de Toledo una carta con copia a todos los obispos de la Corona de Castilla, solicitando una relación de clérigos aptos para nombramientos eclesiásticos. La repitió casi en los mismos términos periódicamente ${ }^{31}$. En agosto de 1603, la circular indicaba:

«Por lo mucho que importa al servicio de Dios y mío y bien de los mys Reynos, que las Iglesias dignidades y otras prebendas se provean en personas de cuyos méritos y calidades se tenga entera satisfacción, teniendo tan grande de vuestra personas y confiando que me hareys relación cierta en cuanto pudiereis saber (pospuestos todos los fines humanos) de los sujetos más capaces para elegir y proveer yo los que más convengan, he querido serviros esta y rogaros afectuosamente y encargamos vuestra conciencia delante de nuestro Señor que como cosa que tanto importa a su servicio y descargo de la mía os informeys con mucho cuidado y atención de la virtud, bondad, charidad, vida, ejemplo, prudencia, modestia, sacerdocio, letras, entendimiento, edad, limpieza de sangre, legitimidad y otras buenas calidades de las personas dignas, calificadas y aprobadas de vuestra diócesis y otras para las dichas Iglesias y prebendas y de la teología o cánones en que fuere su graduación y de donde son naturales, y cómo han procedido y governado en los oficios y ocupaciones que han tenido, haziendo las diligencias que para verificación desto os pareciere necesario, de lo que me enviareis con la más brevedad que podais relación particular a manos de mi infra escripto haziendo distinción de los sujetos más beneméritos y aprobados para las iglesias y de otras dignidades y prebendas, firmadas con vuestro nombre y guardando en todo mucho secreto» ${ }^{32}$.

Con estos datos trabajaba la Cámara de Castilla, que presentaba al rey un listado de candidatos con un breve currículum de cada uno, el valor y las rentas del obispado y el número de parroquias. Para la Cámara, la selección de los posibles prelados era una tarea delicada. En memorial fechado en 13 de junio de 1620 exponían:

«Sabiendo la Cámara lo que Vuestra Majestad, cumpliendo con la obligación de tan christiano y cathólico rey, desea que las provisión las dignidades, beneficios los oficios se hagan en personas de las letras, prudencia y experiencia y de demás partes que se requieren y viendo lo que desdora este intento cualesquier provisión que no sea conforme a aquel, y que no nace del real ánimo de Vuestra Majestad sino de siniestras informaciones, cautelas y extraordinarias diligencias de los que sin las partes y requisitos necesarios, se atreven a pretender las dignidades, beneficios y oficios que Vuestra Majestad provee. Juzga la Cámara que en ninguna cosa podrá servir más a Vuestra Majestad que en hacerle sabedor de semejantes casos quando sucedieren, para que siendo informado de ellos, se prevenga el inconveniente que traen y cese el escándalo que se sigue» ${ }^{33}$.

${ }^{31}$ Cfr. AHN Consejos Libro 5 fols. 87v-88 y Libro 9 fols. 368-368v. Textos semejantes en Libros 5 fols.370v-371, Libro 7 315v-316, Libro 8 fols. 290-290v, Libro 10 fols. 327v-328 y Libro 12 fols. 176v-177.

${ }^{32}$ Cfr. AHN Consejos Libro 5 fol. 370v-371. En la misma línea Vid. AHN Consejos Libro 7 fols. 315v-316v fechado el 18-7-1609 y también el 18-10-1611 en Consejos Libro 8 fols. 290-290v.

${ }^{33}$ Cfr. AHN Consejos L. 15219, II, 8 (8). 
Con la información de la Cámara, el rey elegía al candidato y lo comunicaba directamente al interesado. En la misma fecha o unos días más tarde se informaba a Roma a través del embajador. Confirmado el nombramiento por Roma, al cabo de unos meses, se remitían al designado las cartas ejecutoriales por las que podía tomar posesión del cargo.

\begin{abstract}
«Designada la persona por el rey, la Cámara se lo comunica al electo y se instruye un proceso informativo sobre las cualidades del candidato episcopal y sobre el status ecclesiae, es decir, sobre la situación de la catedral, la ciudad episcopal y la diócesis. Acto seguido se expide al embajador español en Roma un documento de presentación de tal persona para tal obispado con el fin de elevar la presentación a la Curia, donde es examinada por el Consistorio de los cardenales. Aceptada la provisión en el Consistorio, el provisto o su representante abonan las tasas debidas y la Curia expide las bulas, que serán enviadas a la Corte y de allí al interesado (...) Se expiden las cartas ejecutorias para que las bulas tengan efecto» ${ }^{34}$.
\end{abstract}

Según Pérez Bustamante, en la selección de candidatos tenía también influencia directa el confesor del rey ${ }^{35}$. «Aunque legalmente el más alto cargo civil era la presidencia de Castilla, en el terreno efectivo quizás fuera el puesto de confesor real el que confiriera más poder. No se trataba sólo de dirigir la conciencia del monarca en cuanto particular; era de hecho, sino de derecho un cargo de altísima responsabilidad «por cuya mano pasan las provisiones de prebendas, de obispados y todo lo que toca a la conciencia del rey en cuanto a los negocios públicos y gobierno exterior de los reinos (...)» ${ }^{36}$.

Es decir, que aunque era la Cámara del Consejo de Castilla la que formaba las ternas para los cargos de provisión real, en la práctica era el confesor real quien los elegía. (...) Como además fue frecuente que el cargo de confesor real llevara anejo el de presidente del Consejo de la Inquisición, puede comprenderse la suma de poder que en él se concentraba y las apetencias que suscitaba» ${ }^{37}$.

El puesto de confesor real era, por tanto, una pieza fundamental en las elecciones episcopales. Su competencia iba más allá de la dirección de la conciencia del monarca. Era su asesor en todas las materias eclesiásticas ${ }^{38}$. Lo confirma

\footnotetext{
${ }^{34}$ Maximiliano Barrio Gozalo, Los obispos de Castilla y León durante el Antiguo Régimen, o.c. p. 34

35 «El cargo de confesor tuvo en el siglo XVII gran importancia política; los católicos monarcas de la dinastía austriaca demandaban orientaciones a sus directores espirituales, y para acallar escrúpulos de conciencia los colocaban en los Consejos y les hacían intervenir en los asuntos de gobierno». Ciríaco Pérez Bustamante, La España de Felipe III, o.c. p. 141.

${ }^{36}$ Memorial anónimo de 1700.

${ }^{37}$ Antonio DomíngueZ OrTIZ, La Iglesia en España en los siglos XVII y XVIII o.c. pp. 91-92.

38 Vid. Isabelle Poutrin, Los confesores de los Reyes de España: carrera y función (siglos XVI y XVII) en A. L. Cortés Peña-J. L. Bertrán-E. Serrano Martín (EDS.), Religión y poder en la Edad Moderna, Granada, 2005, pp. 67-81.
}

Hispania Sacra, LX

122, julio-diciembre 2008, 703-733, ISSN: 0018-215-X 
el Nuncio Caetani: «Viene así a entender los más importantes negocios de toda esta monarquía y se puede afirmar que de toda la Cristiandad, lo que supone que difícilmente exista hoy un ministro de mayor consideración» ${ }^{39}$.

Competían directamente al confesor materias eclesiásticas como la defensa de regalías, provisión de obispados, elección de ministros, además de los negocios de gobierno relacionados con la conciencia del rey. Fue una figura de frontera entre la intimidad de la cámara real, a la que tenía acceso diario, y los asuntos públicos en los que podía y debía intervenir.

Hombres de confianza de los reyes, con reconocido prestigio personal debido a las capacidades intelectuales de la mayoría de ellos, su cargo fue en muchas ocasiones paso previo al episcopado o su nombramiento como superiores de su orden. Por su intervención en las reformas religiosas y en las relaciones con Roma, necesitaban tener apoyos personales en la Corte, donde algunos ejercieron otros cargos de importancia ${ }^{40}$.

Seis dominicos fueron confesores de Felipe III ${ }^{41}$; entre ellos, ocupó el cargo durante más tiempo Fray Tomás de Aliaga, que lo fue desde 1608 hasta 1621. Fue Consejero de la Suprema Inquisición en 1614 e Inquisidor General en diciembre de $1618^{42}$.

En la documentación aparece con frecuencia citado el confesor real. El rey, pedía su opinión sobre una carta del rector de la Universidad de Salamanca. Le da cuenta sobre la anexión de un beneficio en la diócesis de Valladolid. Le muestra una carta de su embajador en Roma. Solicita que revise una misiva enviada por el capítulo de los Agustinos. Le recuerda una decisión tomada sobre el Monasterio de Las Huelgas de Burgos. Le indica que lea una carta del General de los Benedicti-

\footnotetext{
39 José NaVArRo Latorre, Aproximación a Fray Luis de Aliaga, confesor de Felipe III e Inquisidor General de España, Zaragoza, 1981, p. 14 y Antonio DomínguEZ ORTIZ, La Iglesia en España en los siglos XVII y XVIII o.c. p. 91.

40 Vid. Isabelle Poutrin, I. Los confesores de los Reyes de España, o.c. pp. 67-81

${ }^{41}$ Desde la vuelta de la Corte a Madrid, ocuparon el cargo Fray Gaspar de Córdoba (+1604), Fray Diego Mardones (1604-1606), Fray Jerónimo Javierre (1606-1608) y Fray Luis de Aliaga desde 1608 hasta la muerte del monarca. Mardones y Aliaga habían sido previamente confesores del Duque de Lerma. Vid. Ciríaco Pérez Bustamante, La España de Felipe III, o.c. pp. 143-145.

42 José Navarro Latorre, Aproximación a Fray Luis de Aliaga, o.c. p. 13. Sobre el P. Aliaga A. Domínguez Ortiz indica que «San Juan de Ribera, arzobispo de Valencia, escribió en 1610 una carta a Felipe III previéndole de los abusos a los que daba lugar el entrometimiento de los confesores en juntas y negocios seculares; proponía que se les adjuntasen dos consultores teólogos, que todos ellos fuesen personas desinteresadas y que sólo entendieran de materias de conciencia; (...) precisamente en ese reinado se registraron los mayores abusos, en especial por la codicia y el afán de mando del P. Aliaga, muy mezclado en las intrigas de la época». Antonio Domínguez OrTIZ, La Iglesia en España en los siglos XVII y XVIII o.c.p. 92. Uno de los casos negativos fue la designación de su hermano Fray Isidoro de Aliaga para el arzobispado de Valencia. Vid. Emilio CALlado Estela, Iglesia, poder y sociedad en el siglo XVII: el arzobispo de Valencia Fray Isidoro de Aliaga, Valencia, 2001.
} 
nos ${ }^{43}$. Sólo en una ocasión le consulta sobre Gaspar de Borja, candidato a la diócesis de Jaén en octubre de $1618^{44}$. Es posible que Felipe III solicitara de palabra la opinión de su confesor pero extraña no encontrar más rastros documentales de su actividad en el ámbito de los nombramientos episcopales.

Tras la designación regia, la Santa Sede confirmaba el nombramiento Ordinariamente la Curia aprobaba a los presentados, aunque hubo algunos casos de rechazo ${ }^{45}$.

En 31 de los 107 nombramientos episcopales Felipe III no eligió a candidatos propuestos por la Cámara de Castilla. Es posible, aunque no hay rastro documental, que en algunos casos siguiera el consejo de su confesor.

Los llamados Libros de Iglesia demuestran que el rey concedía cargos eclesiásticos directamente, como premio a los años de servicio a la Corona. Así fue en julio de 1611 nombrando deán de Toledo al hijo de Doña Beatriz Guerra, azafata de la Reina Margarita de Austria. Otorgó 300 ducados de pensión sobre los frutos del obispado de Salamanca al clérigo Diego Zapata, hijo de Don Francisco Zapata, caballerizo del rey ${ }^{46}$. Un ejemplo, una carta suya de 1610 :

«Al Cabildo de la Catedral de Córdoba. Venerable Deán y Cabildo, el Licenciado Don Pedro de Zamora, Presidente de mi Cancillería de Valladolid, me ha hecho relación que el año de 1602 le hize la merced de nombrarle a una ración de essa Iglesia que vacó por promoción de Don Luis de Córdoba al obispado de Salamanca en consideración de los catorce años que sirvió en las Inquisiciones de Navarra y Aragón en el tiempo de las rebuliciones y después diez años en el Consejo de la General Inquisición (...)» ${ }^{47}$.

Esta conducta no le impedía censurar a quienes «se valen de la hacienda, parentescos y amistades» para conseguir nombramientos, como si fuera algo totalmente ajeno a su conducta ${ }^{48}$.

En ocasiones ese comportamiento tuvo malas consecuencias. Veamos una. Juan de Sandoval, sobrino del arzobispo de Toledo, siendo estudiante ordenado de menores, recibió por voluntad de Felipe III la chantría de Alcalá de Henares,

43 Cfr. AHN Consejos Legajo1599 III, 32; Legajo 15201 III,56; Legajo 15202 III, 41; Legajo 15211 III, 27; Legajo 15212 III,15; Legajo 15216 III, 7 respectivamente.

${ }^{44}$ Cfr. AHN Consejos Legajo 15217 III, 58.

45 «La Curia romana se queda con la llave de la confirmación de los electos, de tal manera que ante una coyuntura política adversa o un informe negativo del nuncio se rechaza o se niega a los presentados por el monarca. Unas veces Roma utiliza este derecho para defender la idoneidad de los electos, pero otras muchas los emplea como arma arrojadiza contra la monarquía católica para proteger o defender sus intereses». Maximiliano Barrio Gozalo, El Real Patronato o.c. p. 9 y $74-75$

${ }^{46}$ Cfr. AHN Consejos Libro 8 fol. 252 y 253.

${ }^{47}$ Cfr. AHN Consejos Libro 8 fol. 144v.

${ }^{48}$ Carta al Duque de Taurisano, embajador en Roma, AHN Consejos Libro 8 fol.183v.

Hispania Sacra, LX

122, julio-diciembre 2008, 703-733, ISSN: 0018-215-X 
tras el fallecimiento del doctor Camaray en noviembre de $1612^{49}$. Otras veces, respetando las condiciones exigidas a los candidatos, el rey, el rey no pudo, en febrero de 1605, otorgar a Bartolomé Carrasco de Figueroa el priorato de Canarias, porque el candidato no tenía aprobado dos cursos de Teología ${ }^{50}$.

Conocemos bastantes casos en los que el curriculum era el adecuado para ocupar una sede episcopal. Así consta en la documentación que refleja la actividad de la Cámara de Castilla. Uno fue el obispado de Ciudad Rodrigo, que vacó el año de $1609^{51}$ y el de Orense ${ }^{52}$.

\section{Obispos designados POR Felipe III PARA la Corona de CAstilla}

El estudio pormenorizado de los 107 nombramientos episcopales de acuerdo con la información que aportan los llamados Libros de Iglesia, permite concluir que durante el reinado de Felipe III se produjo relevo episcopal en las 37 sedes de la Corona de Castilla. En algunas diócesis, como Ciudad

\footnotetext{
${ }^{49}$ Cfr. AHN Consejos Libro 9 fols. 86v-87 y AVS Nunciatura en España 338.294 J. OLARRA-M. L. LARRAMENDI, vol. IV, p. 239. Otro caso de herencia tío-sobrino es el siguiente: Al ser designado obispo de Canarias en 1614, el Doctor Antonio Corrionero consiguió que el rey otorgara a su sobrino Antonio Rivera el beneficio que él ocupaba en la iglesia de Valdeolivas (Cuenca). Cfr. AHN Consejos Libro 10 fol. 11 .

${ }^{50}$ Cfr. AHN Consejos Libro 6 fol. 137.

51 «El Doctor Pedro Martínez de Muro, abad de la Iglesia Colegial de Alfaro, de quien el obispo de Cartagena Don Fernando Martínez y el obispo que fue de Málaga Don Juan Alonso informaron a VM que es legítimo de 54 años, persona de muy buen entendimiento, cuerdo, sagaz, virtuoso, de buen ejemplo y condición apacible, buen cristiano, temeroso de Dios, liberal, piadoso, modesto, muy concertado y docto porque llevó en Alcalá primero en licencia de Artes y se graduó de Maestro en ellas, y que en teología llevó también primero en licencia y se graduó doctor en ella y fue colegial mayor en Alcalá y catedrático de Artes y Philosophía moral, y que de allí le sacó el rey que aya gloria para leer la cátedra de vísperas de teología del monasterio de San Lorenzo el Real y en vacando la de prima se la dio. Las quales regentó con gran satisfacción de los religiosos y de las demás personas doctas que concurrieron allí, de donde le proveyó su Md. En dicha Abadía de Alfaro que es de patronazgo real. Y que le tienen por capaz de una iglesia, y visitó por mandado de VM el Monasterio de monjas de Erce que es de patronazgo real, en que procedió con mucha satisfacción de la Cámara, vale su abadía 2000 ducados». Cfr. AHN Consejos Legajo 15214, I, 11(2).

52 «Para el obispado de Orense. El Maestro Fray Plácido de los Santos que fue de la orden de San Benito, tiene 34 años de hábito y es graduado de Maestro en Artes y Teología. Uno de los cuatro Maestros Generales de su Orden y el más antiguo de ellos; fue predicador de la emperatriz con título; ha sido dos veces abad de Madrid y una definidor, leyó 7 años de Teología en Salamanca y ha predicado 16 continuos aquí y 10 en Salamanca y en otras partes con gran aceptación y sus letras son conocidas en todas las Universidades por haber tenido en ellas actos públicos y presidido en muchos. Es docto, virtuoso y muy buen religioso, será de 54 años, hidalgo, calificador de la General Inquisición y predicador de VM, natural de Velorado, y también le nombró la Cámara a VM para el obispado de Mondoñedo que vacó el año de 612 y para el de Calahorra dos vezes que vacó el año de 613 y para el de Osma que vacó el dicho año de 613». AHN Consejos Legajo 15214, I, 11(2).
} 
Rodrigo, Palencia o Coria sólo se nombró un obispo, en otras, como Oviedo o Segovia, hubo hasta 5 y 6 nombramientos respectivamente. La distribución anual es la siguiente:

$\begin{array}{rrrrrrrr}1598 & 1 & 1604 & 4 & 1610 & 4 & 1616 & 10 \\ 1599 & 6 & 1605 & 2 & 1611 & 8 & 1617 & 4 \\ 1600 & 5 & 1606 & 2 & 1612 & 7 & 1618 & 6 \\ 1601 & 3 & 1607 & 6 & 1613 & 6 & 1619 & 3 \\ 1602 & 8 & 1608 & 1 & 1614 & 2 & 1620 & 5 \\ 1603 & 6 & 1609 & 1 & 1615 & 9 & 1621 & 0\end{array}$

Según la documentación podemos concluir que, en 44 de los 107 nombramientos realizados por Felipe III, falta el listado de candidatos que presentaba previamente la Cámara de Castilla al rey. De los otros 63 se conserva la relación de candidatos propuestos al monarca ${ }^{53}$.

En el siguiente cuadro se indica la referencia a los Libros de Iglesia y el Legajo de la Sección de Consejos donde se encuentra la terna presentada al rey u otra referencia documental sobre ese nombramiento; también se señala la página del volumen IV de Eubel-Gauchat donde aparece el nombramiento y dos fechas (la primera corresponde a la designación regia, la segunda a la papal, que aparece en negrita cuando es anterior al nombramiento regio): ${ }^{54}$.

\section{Obispos de la Corona de Castilla nombrados por Felipe III ${ }^{55}$}

\begin{tabular}{|l|c|c|c|l|l|}
\hline $\begin{array}{l}\text { LegAHN/ } \\
\text { pág. } \\
\text { EUBEL } \\
\text { vol.IV }\end{array}$ & LIBRO & FOLIO & FECHAS & NOMBRE & \multicolumn{1}{|c|}{ CARGO } \\
\hline 339 & 4 & $341-342$ & $\begin{array}{l}28 / 3 / 1599 \\
19 / 4 / 1599\end{array}$ & $\begin{array}{l}\text { Bernardo Rojas de } \\
\text { Sandoval, ex obispo } \\
\text { de Jaén. }\end{array}$ & $\begin{array}{l}\text { arzobispado de } \\
\text { Toledo }\end{array}$ \\
\hline
\end{tabular}

${ }^{53} \mathrm{Se}$ ha buscado sin éxito en diversas secciones del AHN. Como hipótesis es posible indicar que en estos casos Felipe III, orientado por su confesor o no, procediera a designar obispos directamente, sin propuesta previa de la Cámara de Castilla.

${ }^{54}$ K. Eubel-P. Gauchat OMC. Hierarchia Catholica medii et recentioris aevi sive Summorum Pontificum, S.R.E. Cardinalium, Ecclesiarum Antistitum Series, Vol. IV, Regensbergianae, 1935.

${ }_{55}$ Cuando no se indique el Legajo de AHN significa que no se ha encontrado la relación de candidatos presentada al rey por la Cámara de Castilla, ni otra noticia documental sobre dicho candidato.

Hispania Sacra, LX

122, julio-diciembre 2008, 703-733, ISSN: 0018-215-X 


\begin{tabular}{|c|c|c|c|c|c|}
\hline $\begin{array}{l}\text { LegAHN/ } \\
\text { pág. } \\
\text { EUBEL } \\
\text { vol.IV }\end{array}$ & LIBRO & FOLIO & FECHAS & NOMBRE & CARGO \\
\hline $\begin{array}{l}15.198, \text { II, } 3 \\
224\end{array}$ & 4 & $343 v$ & $\begin{array}{r}29 / 5 / 1599 \\
17 / 2 / 1599^{56}\end{array}$ & $\begin{array}{l}\text { Doctor Pedro de Castro, } \\
\text { magistral de Toledo } 57\end{array}$ & Obispado de Lugo \\
\hline 243 & 4 & 347 & $\begin{array}{r}14 / 6 / 1599 \\
\mathbf{1} / \mathbf{2} / \mathbf{1 5 9 9}\end{array}$ & $\begin{array}{l}\text { Doctor Diego González } \\
\text { de Samaniego }\end{array}$ & $\begin{array}{l}\text { obispado de } \\
\text { Mondoñedo }\end{array}$ \\
\hline $\begin{array}{l}15.199, \text { II, } 224 \\
194\end{array}$ & & $386 v-387 v$ & $\begin{array}{l}3 / 12 / 1599 \\
10 / 1 / 1600\end{array}$ & $\begin{array}{l}\text { Sancho de Ávila } \\
\text { ex obispo de Cartagena }\end{array}$ & obispado de Jaén \\
\hline $\begin{array}{l}15.199, \text { II }, 22 \\
229\end{array}$ & 4 & $386 v-387 v$ & $\begin{array}{l}3 / 12 / 1599 \\
19 / 1 / 1600\end{array}$ & $\begin{array}{l}\text { Thomás de Borja, } \\
\text { canónigo e inquisidor de } \\
\text { Málaga }\end{array}$ & $\begin{array}{l}\text { obispado de } \\
\text { Málaga, } \\
1603 \text { Zaragoza }\end{array}$ \\
\hline $\begin{array}{l}15.199, \text { II ,22 } \\
136\end{array}$ & 4 & 419 & $\begin{array}{l}11 / 4 / 1600 \\
\mathbf{2 3 / 1 / 1 6 0 0}\end{array}$ & $\begin{array}{l}\text { Licenciado Juan de } \\
\text { Zúñiga, Consejo } \\
\text { Inquisición }\end{array}$ & $\begin{array}{l}\text { obispado de } \\
\text { Cartagena }\end{array}$ \\
\hline $\begin{array}{l}15.200, \mathrm{I}, 4(2) \\
123\end{array}$ & 5 & $37-37 v$ & $\begin{array}{r}10 / 1600 \\
11 / 9 / 1600\end{array}$ & $\begin{array}{l}\text { Antonio Zapata, ex } \\
\text { obispo de Pamplona }\end{array}$ & arzobispado Burgos \\
\hline $\begin{array}{l}15.200, \mathrm{I}, 7 \\
271\end{array}$ & 5 & $38-38 v$ & $\begin{array}{r}10 / 1600 \\
24 / 9 / 1600\end{array}$ & $\begin{array}{l}\text { Mateo de Burgos, } \\
\text { Comisario General OF }\end{array}$ & $\begin{array}{l}\text { obispado de } \\
\text { Pamplona }\end{array}$ \\
\hline $\begin{array}{l}15.200, \text { II, } 265 \\
\text { y III, } 66,6 \\
348\end{array}$ & & $54 \mathrm{v}$ & $\begin{array}{l}26 / 3 / 1600 \\
11 / 5 / 1601\end{array}$ & $\begin{array}{l}\text { Doctor Terrones del } \\
\text { Cano,capellán predicador } \\
\text { real }\end{array}$ & obispado de Tuy \\
\hline $\begin{array}{l}15.200, \text { II, } 26 \\
\text { y III, } 66,6 \\
204\end{array}$ & 5 & $62 \mathrm{v}$ & $\begin{array}{l}11 / 4 / 1601 \\
30 / 4 / 1601\end{array}$ & $\begin{array}{l}\text { Hernando Niño de } \\
\text { Guevara Consejo Estado } \\
\text { e Inquisidor }\end{array}$ & $\begin{array}{l}\text { arzobispado de } \\
\text { Sevilla }\end{array}$ \\
\hline $\begin{array}{l}15.200, \text { II, } 26 \\
159\end{array}$ & 5 & 64 & $\begin{array}{l}30 / 4 / 1601 \\
13 / 8 / 1601\end{array}$ & $\begin{array}{l}\text { Doctor Andrés Pacheco, } \\
\text { ex obispo de Segovia }\end{array}$ & $\begin{array}{l}\text { obispado de } \\
\text { Cuenca }\end{array}$ \\
\hline $\begin{array}{l}15201, \text { III, } 30,3 \\
310\end{array}$ & 5 & 64 & $\begin{array}{l}30 / 4 / 1601 \\
27 / 8 / 1601\end{array}$ & $\begin{array}{l}\text { Maximiliano de Austria, } \\
\text { ex obispo de Cádiz }\end{array}$ & $\begin{array}{l}\text { obispado de } \\
\text { Segovia }\end{array}$ \\
\hline $\begin{array}{l}15202, \mathrm{I}, 14 \\
164\end{array}$ & 5 & $158-158 \mathrm{v}$ & $26 / 4 / 1602$ & $\begin{array}{l}\text { Tomás de Borja, ex } \\
\text { obispo de Málaga }\end{array}$ & $\begin{array}{l}\text { obispado de } \\
\text { Córdoba, }\end{array}$ \\
\hline
\end{tabular}

56 Figuran en negrita las fechas de nombramientos papales cuando las designaciones son anteriores al nombramiento regio. Ordinariamente la designación correspondía al rey y la confirmación a Roma.

${ }^{57}$ Figuran en letra cursiva los candidatos nombrados previamente por el Papa sin terna previa y corroborados posteriormente por Felipe III.

${ }^{58}$ No aparece citado en Eubel-Gauchat. 


\begin{tabular}{|c|c|c|c|c|c|}
\hline $\begin{array}{l}\text { LegAHN/ } \\
\text { pág. } \\
\text { EUBEL } \\
\text { vol.IV }\end{array}$ & LIBRO & FOLIO & FECHAS & NOMBRE & CARGO \\
\hline 229 & 5 & $160 \mathrm{v}$ & $\begin{array}{l}7 / 5 / 1602 \\
9 / 5 / 1603\end{array}$ & $\begin{array}{l}\text { Juan Alonso de Moscoso, } \\
\text { ex obispo de León }\end{array}$ & $\begin{array}{l}\text { obispado de } \\
\text { Málaga }\end{array}$ \\
\hline $\begin{array}{l}15.202, \text { II }, 2(3) \\
218\end{array}$ & --- & ---.59 & $\begin{array}{l}30 / 5 / 1602 \\
12 / 5 / 1603\end{array}$ & $\begin{array}{l}\text { Fray Andrés de Casso, } \\
\text { provincial dominico }\end{array}$ & obispado de León \\
\hline $\begin{array}{l}15.202, \mathrm{I}, 24(2) \\
79\end{array}$ & 5 & $166 v$ & $\begin{array}{l}30 / 5 / 1602 \\
26 / 8 / 1602\end{array}$ & $\begin{array}{l}\text { Fray Juan de Portocarrero, } \\
\text { OF confesor emperatriz }\end{array}$ & $\begin{array}{l}\text { obispado de } \\
\text { Almería }\end{array}$ \\
\hline $\begin{array}{l}15202, \mathrm{I}, 13 \\
192\end{array}$ & 5 & 178 & $\begin{array}{l}10 / 9 / 1602 \\
\mathbf{2 6 / 6 / 1 6 0 2}\end{array}$ & $\begin{array}{l}\text { Licenciado Gómez de } \\
\text { Figueroa, rector U. } \\
\text { Salamanca }\end{array}$ & obispado de Cádiz \\
\hline $\begin{array}{l}15.202, \text { II }, 2(3) \\
268\end{array}$ & 5 & $178 v$ & $\begin{array}{r}10 / 9 / 1602 \\
15 / 11 / 1602\end{array}$ & $\begin{array}{l}\text { Enrique Enríquez, } \\
\text { Provincial OSA }\end{array}$ & obispado de Osma \\
\hline $\begin{array}{l}15.202, \mathrm{I}, 10 \\
269\end{array}$ & 5 & $245 v-246$ & $\begin{array}{l}10 / 9 / 1602 \\
7 / 10 / 1602\end{array}$ & $\begin{array}{l}\text { Andrés Fernández de } \\
\text { Córdoba, auditor de la } \\
\text { Rota }\end{array}$ & $\begin{array}{l}\text { obispado de } \\
\text { Badajoz }\end{array}$ \\
\hline $\begin{array}{l}15.202, \text { II, 2(3) } \\
300\end{array}$ & 5 & $246 v-247$ & $\begin{array}{l}17 / 10 / 1602 \\
20 / 11 / 1602\end{array}$ & $\begin{array}{l}\text { Luis Fernández de } \\
\text { Córdoba, deán catedral } \\
\text { Córdoba }\end{array}$ & $\begin{array}{l}\text { obispado de } \\
\text { Salamanca }\end{array}$ \\
\hline 126 & 5 & $268 \mathrm{v}$ & $\begin{array}{r}10 / 12 / 1602 \\
13 / 1 / 1603\end{array}$ & $\begin{array}{l}\text { Alonso de Coloma, ex } \\
\text { obispo de Barcelona }\end{array}$ & $\begin{array}{l}\text { obispado de } \\
\text { Cartagena }\end{array}$ \\
\hline $\begin{array}{l}15.202, \text { II, 3(2) } \\
158\end{array}$ & 5 & $286 v-290$ & $\begin{array}{l}22 / 2 / 1603 \\
21 / 4 / 1603\end{array}$ & $\begin{array}{l}\text { Maximiliano de Austria, } \\
\text { ex obispo de Segovia }\end{array}$ & $\begin{array}{l}\text { arzobispado de } \\
\text { Santiago de } \\
\text { Compostela }\end{array}$ \\
\hline $\begin{array}{l}15.203 \text { III,6 } \\
267\end{array}$ & 5 & $291 v-293$ & $\begin{array}{l}23 / 2 / 1603 \\
16 / 4 / 1603\end{array}$ & $\begin{array}{l}\text { Ldo. Alonso Martínez de } \\
\text { la Torre, orden Santiago }\end{array}$ & obispado de Oviedo \\
\hline $\begin{array}{l}15.203, \mathrm{I}, 11 \\
164\end{array}$ & --- & ---- & $\begin{array}{l}19 / 3 / 1603 \\
30 / 7 / 1603\end{array}$ & $\begin{array}{l}\text { Pablo de Laguna, } \\
\text { Presidente del Consejo } \\
\text { de Indias }\end{array}$ & $\begin{array}{l}\text { obispado de } \\
\text { Córdoba }\end{array}$ \\
\hline $\begin{array}{l}15.203, \text { III }, 23 \\
229\end{array}$ & 5 & 305-306 & $\begin{array}{r}29 / 3 / 1603 \\
9 / 5 / 1603\end{array}$ & $\begin{array}{l}\text { Juan Alonso de Moscoso, } \\
\text { ex obispo de León }\end{array}$ & obispado de Málaga \\
\hline $\begin{array}{l}15.203, \mathrm{I}, 11 \\
310\end{array}$ & 5 & 353 & $\begin{array}{r}6 / 7 / 1603 \\
15 / 8 / 1603\end{array}$ & $\begin{array}{l}\text { Pedro de Castro, ex } \\
\text { obispo de Lugo }\end{array}$ & $\begin{array}{l}\text { obispado de } \\
\text { Segovia }\end{array}$ \\
\hline
\end{tabular}

${ }^{59}$ De varios obispos no se indica libro y folio; de ellos consta que hubo una propuesta de candidatos por parte de la Cámara de Castilla al rey y éste eligió a uno, aunque finalmente, de hecho no resultara nombrado obispo para dicha diócesis según los Libros de Iglesia.

Hispania Sacra, LX

122, julio-diciembre 2008, 703-733, ISSN: 0018-215-X 


\begin{tabular}{|c|c|c|c|c|c|}
\hline $\begin{array}{l}\text { LegAHN/ } \\
\text { pág. } \\
\text { EUBEL } \\
\text { vol.IV }\end{array}$ & LIBRO & FOLIO & FECHAS & NOMBRE & CARGO \\
\hline $\begin{array}{l}15.203, \mathrm{I}, 11 \\
224\end{array}$ & 5 & 353 & $\begin{array}{r}6 / 7 / 1603 \\
27 / 8 / 1603\end{array}$ & $\begin{array}{l}\text { Juan García de } \\
\text { Valdemoro, canónigo } \\
\text { Alcalá }\end{array}$ & obispado de Lugo \\
\hline $\begin{array}{l}15.203, \text { II, } 4 \\
142\end{array}$ & 5 & $402-403$ & $\begin{array}{r}3 / 11 / 1603 \\
10 / 12 / 1603\end{array}$ & $\begin{array}{l}\text { Pedro de Carvajal, deán } \\
\text { de Toledo }\end{array}$ & $\begin{array}{l}\text { obispado de Coria } \\
\text { Cáceres }\end{array}$ \\
\hline 123 & 5 & $443-443 v$ & $28 / 2 / 1604$ & $\begin{array}{l}\text { Maestro Fr. Alonso } \\
\text { Enríquez Armendáriz, } \\
\text { mercedario. }{ }^{60}\end{array}$ & $\begin{array}{l}\text { obispado auxiliar } \\
\text { de Burgos }\end{array}$ \\
\hline 123 & 6 & $65-66 v$ & $\begin{array}{r}2 / 9 / 1604 \\
20 / 10 / 1604 \\
\end{array}$ & $\begin{array}{l}\text { Alonso Manrique, } \\
\text { residente en esa corte }\end{array}$ & $\begin{array}{l}\text { arzobispado de } \\
\text { Burgos }\end{array}$ \\
\hline $\begin{array}{l}15.204, \text { II, } 12 \\
267\end{array}$ & 6 & $114 \mathrm{v}$ & $\begin{array}{l}7 / 11 / 1604 \\
12 / 1 / 1605\end{array}$ & $\begin{array}{l}\text { Doctor Juan Álvarez de } \\
\text { Caldás, del Consejo } \\
\text { Inquisición }\end{array}$ & obispado de Oviedo \\
\hline $\begin{array}{l}15205, \mathrm{I}, 3 \\
151\end{array}$ & 6 & 182 & $\begin{array}{r}6 / 7 / 1605 \\
31 / 8 / 1605 \\
\end{array}$ & $\begin{array}{l}\text { Fray Pedro Ponce de } \\
\text { León OP }\end{array}$ & $\begin{array}{l}\text { obispado de Ciudad } \\
\text { Rodrigo }\end{array}$ \\
\hline $\begin{array}{l}15.205, \text { II }, 8(1) \\
198\end{array}$ & 6 & $260 v-261$ & $\begin{array}{r}12 / 11 / 1605 \\
16 / 1 / 1606\end{array}$ & $\begin{array}{l}\text { Juan de Orozco y } \\
\text { Covarrubias, ex obispo } \\
\text { Agrigento }\end{array}$ & obispado de Guadix \\
\hline $\begin{array}{l}15.205 \mathrm{II}, 3(12) \\
311\end{array}$ & 6 & $305 \mathrm{v}$ & $\begin{array}{l}29 / 3 / 1606 \\
\mathbf{1 6} / \mathbf{1} / \mathbf{1 6 0 6} \\
\end{array}$ & $\begin{array}{l}\text { Fray Mateo de Burgos, } \\
\text { ex obispo de Pamplona }\end{array}$ & $\begin{array}{l}\text { obispado de } \\
\text { Sigüenza }\end{array}$ \\
\hline $\begin{array}{l}15.205 \text { III,52 } \\
271\end{array}$ & 6 & $305 v$ & $\begin{array}{l}29 / 3 / 1606 \\
\mathbf{3 0} / \mathbf{1} / \mathbf{1 6 0 6}\end{array}$ & $\begin{array}{l}\text { Antonio Venegas, ex } \\
\text { Consejo de Inquisición }\end{array}$ & $\begin{array}{l}\text { obispado de } \\
\text { Pamplona }\end{array}$ \\
\hline $\begin{array}{l}15.206, \text { II, } 3 \\
164\end{array}$ & 6 & $385 v-386$ & $\begin{array}{l}3 / 1 / 1607 \\
7 / 2 / 1607\end{array}$ & $\begin{array}{l}\text { Diego de Mardones, OP } \\
\text { confesor del rey }\end{array}$ & $\begin{array}{l}\text { obispado de } \\
\text { Córdoba }\end{array}$ \\
\hline $\begin{array}{l}15.206, \text { II, } 4(2) \\
136\end{array}$ & 7 & $13-13 v$ & $\begin{array}{l}26 / 6 / 1607 \\
13 / 8 / 1607\end{array}$ & $\begin{array}{l}\text { Francisco Martínez de } \\
\text { Ceniceros, ex obispo de } \\
\text { Canarias }\end{array}$ & $\begin{array}{l}\text { obispado de } \\
\text { Cartagena }\end{array}$ \\
\hline 132 & 7 & $13 v-14$ & $\begin{array}{r}26 / 6 / 1607 \\
3 / 9 / 1607 \\
\end{array}$ & $\begin{array}{l}\text { Fray Francisco de Sossa, } \\
\text { ex General OF }\end{array}$ & $\begin{array}{l}\text { obispado de } \\
\text { Canaria }\end{array}$ \\
\hline 357 & 7 & $14 \mathrm{v}-15$ & $\begin{array}{l}26 / 6 / 1607 \\
13 / 8 / 1607\end{array}$ & $\begin{array}{l}\text { Licenciado Juan Vigil de } \\
\text { Quiñones, Inquisidor Gral }\end{array}$ & $\begin{array}{l}\text { obispado de } \\
\text { Valladolid }\end{array}$ \\
\hline
\end{tabular}

${ }^{60}$ No aparece citado en Eubel-Gauchat. 


\begin{tabular}{|c|c|c|c|c|c|}
\hline $\begin{array}{l}\text { LegAHN/ } \\
\text { pág. } \\
\text { EUBEL } \\
\text { vol.IV }\end{array}$ & LIBRO & FOLIO & FECHAS & NOMBRE & CARGO \\
\hline 218 & 7 & $96-96 \mathrm{v}$ & $\begin{array}{r}29 / 12 / 1607 \\
3 / 3 / 1608\end{array}$ & $\begin{array}{l}\text { Doctor Francisco de } \\
\text { Terrones del Caño ex } \\
\text { obispo Tuy }\end{array}$ & obispado de León \\
\hline 348 & 7 & $96 v-97$ & $\begin{array}{r}29 / 12 / 1607 \\
10 / 3 / 1608\end{array}$ & $\begin{array}{l}\text { Fray Prudencio de } \\
\text { Sandoval,OSB cronista } \\
\text { real }\end{array}$ & obispado de Tuy \\
\hline 271 & 7 & $129 \mathrm{v}$ & $\begin{array}{l}13 / 4 / 1608 \\
\mathbf{1 1} / \mathbf{2} / \mathbf{1 6 0 8}\end{array}$ & $\begin{array}{l}\text { Phelipe de Taxis,Consejo } \\
\text { Inquisición y Cruzada }\end{array}$ & $\begin{array}{l}\text { obispado de } \\
\text { Palencia }\end{array}$ \\
\hline $\begin{array}{l}15.208, \mathrm{I}, 17 \\
132\end{array}$ & 8 & 15 & $\begin{array}{r}25 / 11 / 1609 \\
26 / 4 / 1610\end{array}$ & $\begin{array}{l}\text { Ldo Nicolás Valdés } \\
\text { Carriazo cap real Freyle } \\
\text { Santiago }\end{array}$ & $\begin{array}{l}\text { obispado de } \\
\text { Canaria }\end{array}$ \\
\hline $\begin{array}{l}15208, \mathrm{I}, 6(1) \\
376\end{array}$ & 8 & $41 v-42$ & $\begin{array}{r}4 / 2 / 1610 \\
29 / 3 / 1610\end{array}$ & $\begin{array}{l}\text { Fray Pedro Ponce de } \\
\text { León,ex obispo de } \\
\text { Ciudad Rodrigo }\end{array}$ & $\begin{array}{l}\text { obispado de } \\
\text { Zamora }\end{array}$ \\
\hline $\begin{array}{l}1208, \text { I, } 17 \text { y } \\
15209 \text { III, } 11 \\
151\end{array}$ & --- & ---- & $\begin{array}{l}30 / 4 / 1609 \\
26 / 5 / 1609\end{array}$ & $\begin{array}{l}\text { Dr. Sobrino, magistral de } \\
\text { Valladolid }^{61}\end{array}$ & $\begin{array}{l}\text { obispado Ciudad } \\
\text { Rodrigo }\end{array}$ \\
\hline 282 & --- & ---- & $\begin{array}{r}6 / 3 / 1610 \\
21 / 6 / 1610 \\
\end{array}$ & $\begin{array}{l}\text { Enrique Enríquez, obispo } \\
\text { de Osma }\end{array}$ & obispado Plasencia \\
\hline 268 & 8 & $96 \mathrm{v}$ & $\begin{array}{r}15 / 5 / 1610 \\
5 / 7 / 1610\end{array}$ & $\begin{array}{l}\text { Ldo. Fernando de } \\
\text { Azevedo, del Consejo de } \\
\text { Inquisición }\end{array}$ & obispado de Osma \\
\hline $\begin{array}{l}15208 \text { III, } 39 \\
204\end{array}$ & 8 & $97 v-98$ & $\begin{array}{r}15 / 5 / 1610 \\
5 / 7 / 1610\end{array}$ & $\begin{array}{l}\text { Pedro de Castro y } \\
\text { Quiñones, ex arzobispo } \\
\text { Granada }\end{array}$ & $\begin{array}{l}\text { arzobispado de } \\
\text { Sevilla }\end{array}$ \\
\hline 196 & 8 & $98-99 v$ & $\begin{array}{l}15 / 5 / 1610 \\
19 / 6 / 1610 \\
\end{array}$ & $\begin{array}{l}\text { Fray Pedro González de } \\
\text { Mendoza, comisario OF }\end{array}$ & $\begin{array}{l}\text { obispado de } \\
\text { Granada }\end{array}$ \\
\hline $\begin{array}{l}15210, \mathrm{I}, 8(1) \\
198\end{array}$ & 8 & 250 & $\begin{array}{r}2 / 7 / 1611 \\
10 / 10 / 1611\end{array}$ & $\begin{array}{l}\text { Nicolás de Valdés y } \\
\text { Carriazo, obispo de } \\
\text { Canarias }\end{array}$ & obispado de Guadix \\
\hline $\begin{array}{l}15210, I, 7(1) \\
311\end{array}$ & 8 & $259 v-260$ & $\begin{array}{r}17 / 8 / 1611 \\
10 / 10 / 1611\end{array}$ & $\begin{array}{l}\text { Antonio Venegas, obispo } \\
\text { de Pamplona }\end{array}$ & $\begin{array}{l}\text { Obispado de } \\
\text { Sigüenza }\end{array}$ \\
\hline
\end{tabular}

${ }^{61}$ El nombramiento pontificio señala a Antonio Idiaquez Manrique.

Hispania Sacra, LX

122, julio-diciembre 2008, 703-733, ISSN: 0018-215-X 


\begin{tabular}{|c|c|c|c|c|c|}
\hline $\begin{array}{l}\text { LegAHN/ } \\
\text { pág. } \\
\text { EUBEL } \\
\text { vol.IV }\end{array}$ & LIBRO & FOLIO & FECHAS & NOMBRE & CARGO \\
\hline 15210, II, $2(1)$ & 8 & $286 \mathrm{v}$ & $8 / 10 / 1611$ & $\begin{array}{l}\text { Gómez de Figueroa, } \\
\text { obispo de Cádiz }{ }^{62}\end{array}$ & obispo de Segovia \\
\hline $\begin{array}{l}15208 \text { III, } 58 \\
15210 \text { III, } 14 \\
132\end{array}$ & 8 & 287 & $\begin{array}{r}8 / 10 / 1611 \\
14 / 11 / 1611\end{array}$ & $\begin{array}{l}\text { Doctor Lope de Velasco, } \\
\text { prior de Roncesvallesa }\end{array}$ & obispo de Canaria \\
\hline $\begin{array}{l}15210 \mathrm{I}, 6 \\
103\end{array}$ & 8 & $301 v$ & $\begin{array}{r}30 / 10 / 1611 \\
\mathbf{1 7 / 8 / 1 6 1 1}\end{array}$ & $\begin{array}{l}\text { Fray Sebastián de } \\
\text { Bricianos, OF }\end{array}$ & obispado de Orense \\
\hline $\begin{array}{l}15210, \text { II, 5(1) } \\
271\end{array}$ & 8 & 313 & $\begin{array}{r}14 / 12 / 1611 \\
27 / 2 / 1612\end{array}$ & $\begin{array}{l}\text { Fray Prudencio de } \\
\text { Sandoval, obispo de } \\
\text { Tuy,cronista }\end{array}$ & $\begin{array}{l}\text { obispado de } \\
\text { Pamplona }\end{array}$ \\
\hline $\begin{array}{l}15210, \text { II } 4(1) \\
269\end{array}$ & 8 & $337 v$ & $\begin{array}{l}12 / 10 / 1611 \\
28 / 11 / 1611\end{array}$ & $\begin{array}{l}\text { Ldo. Juan Beltrán de } \\
\text { Guevara, arzobispo de } \\
\text { Salerno }\end{array}$ & $\begin{array}{l}\text { obispado de } \\
\text { Badajoz }\end{array}$ \\
\hline $\begin{array}{l}15211, \mathrm{I}, 24 \\
65\end{array}$ & 8 & 381 & $\begin{array}{r}4 / 4 / 1612 \\
14 / 5 / 1612\end{array}$ & $\begin{array}{l}\text { Doctor Juan Álvarez de } \\
\text { Caldas, obispo de Oviedo }\end{array}$ & obispado de Ávila \\
\hline $\begin{array}{l}15211, \mathrm{I}, 22 \\
243\end{array}$ & 9 & 8 & $\begin{array}{r}5 / 5 / 1612 \\
18 / 6 / 1612\end{array}$ & $\begin{array}{l}\text { Doctor Alonso Mejía de } \\
\text { Tovar,capellán Descalzas } \\
\text { reales }\end{array}$ & $\begin{array}{l}\text { obispado de } \\
\text { Mondoñedo }\end{array}$ \\
\hline $\begin{array}{l}15211, \mathrm{I}, 9 \\
348\end{array}$ & 9 & 23 & $\begin{array}{l}30 / 5 / 1612 \\
16 / 7 / 1612\end{array}$ & $\begin{array}{l}\text { Doctor Juan García de } \\
\text { Valdemora y Labuena, } \\
\text { ob Lugo }\end{array}$ & obispado de Tuy \\
\hline $\begin{array}{l}15211, \text { III }, 36 \\
224\end{array}$ & 9 & $30 \mathrm{v}$ & $\begin{array}{r}6 / 6 / 1612 \\
17 / 9 / 1612\end{array}$ & $\begin{array}{l}\text { Ldo. Alonso López Gallo, } \\
\text { admón hospital } \\
\text { Montesdoca }\end{array}$ & obispado de Lugo \\
\hline $\begin{array}{l}15211, \text { III } 23 \\
268\end{array}$ & 9 & $35 v$ & $\begin{array}{l}23 / 6 / 1612 \\
17 / 9 / 1612\end{array}$ & Francisco de la Cueva, OP & obispado de Oviedo \\
\hline $\begin{array}{l}15211, \mathrm{I}, 23 \\
192\end{array}$ & 9 & $39-39 v$ & $\begin{array}{l}29 / 6 / 1612 \\
20 / 8 / 1612\end{array}$ & $\begin{array}{l}\text { LicenciadoJuan de } \\
\text { Cuenca, freyle Orden de } \\
\text { Santiago }\end{array}$ & obispado de Cádiz \\
\hline $\begin{array}{l}15211, \mathrm{I}, 17(2) \\
310\end{array}$ & 9 & $94 \mathrm{v}-95$ & $\begin{array}{r}19 / 11 / 1612 \\
4 / 2 / 1613\end{array}$ & $\begin{array}{l}\text { Doctor Antonio Idiaquez, } \\
\text { obispo de Ciudad Rodrigo }\end{array}$ & $\begin{array}{l}\text { obispado de } \\
\text { Segovia }\end{array}$ \\
\hline
\end{tabular}

${ }^{62}$ No aparece citado en Eubel-Gauchat. 


\begin{tabular}{|c|c|c|c|c|c|}
\hline $\begin{array}{l}\text { LegAHN/ } \\
\text { pág. } \\
\text { EUBEL } \\
\text { vol.IV }\end{array}$ & LIBRO & FOLIO & FECHAS & NOMBRE & CARGO \\
\hline $\begin{array}{l}15.212, \mathrm{I}, 2 \\
123\end{array}$ & 9 & 133 & $\begin{array}{l}6 / 3 / 1613 \\
2 / 6 / 1613\end{array}$ & $\begin{array}{l}\text { Hernando de Azevedo, } \\
\text { obispo de Osma }\end{array}$ & $\begin{array}{l}\text { arzobispado de } \\
\text { Burgos }\end{array}$ \\
\hline $\begin{array}{l}15212, \mathrm{I}, 3 \\
128\end{array}$ & 9 & $191 v-192$ & $\begin{array}{l}23 / 5 / 1613 \\
29 / 7 / 1613\end{array}$ & $\begin{array}{l}\text { Ldo. Pedro de Zamora, } \\
\text { Presidente Chancillería } \\
\text { Valladolid }\end{array}$ & $\begin{array}{l}\text { obispado de } \\
\text { Calahorra-La } \\
\text { Calzada }\end{array}$ \\
\hline $\begin{array}{l}15211, \mathrm{I}, 17(2) \\
151\end{array}$ & 9 & 201-201v & $\begin{array}{l}15 / 6 / 1613 \\
12(8 / 1613\end{array}$ & $\begin{array}{l}\text { Doctor Jerónimo Ruiz de } \\
\text { Camargo Magist Ávila }\end{array}$ & $\begin{array}{l}\text { obispado Ciudad } \\
\text { Rodrigo }\end{array}$ \\
\hline $\begin{array}{l}15121 \text { III,37 } \\
218\end{array}$ & 9 & 205 & $\begin{array}{l}29 / 6 / 1613 \\
23 / 9 / 1613\end{array}$ & $\begin{array}{l}\text { Dr. Alonso González, } \\
\text { abad colegiata Aguilar } \\
\text { Campoo }\end{array}$ & obispado de León \\
\hline $\begin{array}{l}15.212, \text { II, } 2 \\
\text { y III, } 51 \\
268\end{array}$ & 9 & $286 \mathrm{v}$ & $\begin{array}{r}15 / 11 / 1613 \\
23 / 9 / 1613\end{array}$ & Francisco de Sosa & obispado de Osma \\
\hline $\begin{array}{l}15212, \text { II, } 17(5) \\
128\end{array}$ & 9 & 290 & $\begin{array}{r}28 / 11 / 1613 \\
17 / 2 / 1614\end{array}$ & $\begin{array}{l}\text { Dr. Pedro González del } \\
\text { Castillo magistral Cuenca }\end{array}$ & $\begin{array}{l}\text { obispado de } \\
\text { Calahorra }\end{array}$ \\
\hline $\begin{array}{l}15.213, \mathrm{I}, 14 \\
132\end{array}$ & 10 & 11 & $\begin{array}{l}23 / 8 / 1614 \\
6 / 10 / 1614\end{array}$ & $\begin{array}{l}\text { Dr Antonio Corrionero, } \\
\text { Audiencia Sevilla }\end{array}$ & $\begin{array}{l}\text { obispado de } \\
\text { Canaria }\end{array}$ \\
\hline $15.214, \mathrm{I}, 12$ & ---- & ---- & $22 / 4 / 1615$ & $\begin{array}{l}\text { Dr. Gamarra, obispo } \\
\text { de Cartagena }\end{array}$ & $\begin{array}{l}\text { obispado de } \\
\text { Astorga }\end{array}$ \\
\hline $\begin{array}{l}15.213, \text { II, } 6 \\
229\end{array}$ & 10 & $67 v-68$ & $\begin{array}{r}31 / 12 / 1614 \\
9 / 2 / 1615\end{array}$ & $\begin{array}{l}\text { Ldo.Luis Fernández de } \\
\text { Córdoba, obispo } \\
\text { Salamanca }\end{array}$ & obispado de Málaga \\
\hline $\begin{array}{l}15.213, \text { II, } 10 \\
311\end{array}$ & 10 & $71 v-72$ & $\begin{array}{l}11 / 1 / 1615 \\
20 / 7 / 1615\end{array}$ & $\begin{array}{l}\text { Sancho Dávila, obispo de } \\
\text { Jaén }\end{array}$ & $\begin{array}{l}\text { obispado de } \\
\text { Sigüenza }\end{array}$ \\
\hline $\begin{array}{l}15.214, \text { II, } 3 \\
98\end{array}$ & --- & ---- & $\begin{array}{r}8 / 8 / 1615 \\
27 / 2 / 1616\end{array}$ & $\begin{array}{l}\text { Dr. Alonso Mejía de } \\
\text { Tovar, obispo de } \\
\text { Mondoñedo }\end{array}$ & $\begin{array}{l}\text { obispado de } \\
\text { Astorga }\end{array}$ \\
\hline $\begin{array}{l}15.213, \text { II, } 3 \\
158\end{array}$ & 10 & 115 & $\begin{array}{l}26 / 2 / 1615 \\
12 / 1 / 1615\end{array}$ & $\begin{array}{l}\text { Juan Beltrán de Guevara, } \\
\text { obispo de Badajoz }\end{array}$ & $\begin{array}{l}\text { arzobispado } \\
\text { Santiago }\end{array}$ \\
\hline $\begin{array}{l}15.214, \mathrm{I}, 14 \\
300\end{array}$ & 10 & $143 \mathrm{v}$ & $\begin{array}{r}1 / 5 / 1615 \\
6 / 7 / 165\end{array}$ & $\begin{array}{l}\text { Fray Diego Ordoñez, } \\
\text { obispo de Jaca }\end{array}$ & $\begin{array}{l}\text { obispado de } \\
\text { Salamanca }\end{array}$ \\
\hline
\end{tabular}

${ }^{63}$ No aparece citado en Eubel-Gauchat.

Hispania Sacra, LX

122, julio-diciembre 2008, 703-733, ISSN: 0018-215-X 


\begin{tabular}{|c|c|c|c|c|c|}
\hline $\begin{array}{l}\text { LegAHN/ } \\
\text { pág. } \\
\text { EUBEL } \\
\text { vol.IV }\end{array}$ & LIBRO & FOLIO & FECHAS & NOMBRE & CARGO \\
\hline $\begin{array}{l}15.214, \mathrm{I}, 12 \\
194\end{array}$ & 10 & $154 \mathrm{v}-155$ & $\begin{array}{r}28 / 5 / 1615 \\
3 / 8 / 1615\end{array}$ & $\begin{array}{l}\text { Doctor Francisco Mtnez } \\
\text { de Ceniceros, obispo de } \\
\text { Cartagena }\end{array}$ & obispado de Jaén \\
\hline $\begin{array}{l}15.213, \text { II, } 13 \\
136\end{array}$ & 10 & $166-166 \mathrm{v}$ & $\begin{array}{l}20 / 6 / 1615 \\
17 / 8 / 1615\end{array}$ & $\begin{array}{l}\text { Doctor Gamarra, cura de } \\
\text { palacio y capellán real }\end{array}$ & $\begin{array}{l}\text { obispado de } \\
\text { Cartagena (Murcia) }\end{array}$ \\
\hline $\begin{array}{l}15.213, \text { II, } 13 \\
269\end{array}$ & 10 & $197-197 \mathrm{v}$ & $\begin{array}{r}29 / 8 / 1615 \\
16 / 11 / 1615\end{array}$ & $\begin{array}{l}\text { Doctor Cristóbal de } \\
\text { Lovera, abad colegiata } \\
\text { Lerma }\end{array}$ & $\begin{array}{l}\text { obispado de } \\
\text { Badajoz }\end{array}$ \\
\hline $\begin{array}{l}15215, \text { III, } 15 \\
196\end{array}$ & 10 & $259 v-260$ & $\begin{array}{r}14 / 12 / 1615 \\
24 / 2 / 1616 \\
\end{array}$ & $\begin{array}{l}\text { Felipe de Tassis, obispo } \\
\text { de Palencia }\end{array}$ & $\begin{array}{l}\text { arzobispo de } \\
\text { Granada }\end{array}$ \\
\hline $\begin{array}{l}15215, \text { III, } 3 \\
\text { y } 54 \\
271\end{array}$ & 10 & $260-260 v$ & $\begin{array}{r}14 / 12 / 1615 \\
29 / 2 / 1616\end{array}$ & $\begin{array}{l}\text { Fray Joseph González, } \\
\text { OP y confesor del } \\
\text { príncipe }\end{array}$ & $\begin{array}{l}\text { obispado de } \\
\text { Palencia }\end{array}$ \\
\hline $\begin{array}{l}15.214, \text { II, } 13 \\
14 \\
65\end{array}$ & 10 & $274 v$ & $\begin{array}{r}4 / 1 / 1616 \\
30 / 5 / 1616\end{array}$ & $\begin{array}{l}\text { Doctor Francisco de } \\
\text { Gamarra, obispo de } \\
\text { Cartagena }\end{array}$ & obispado de Ávila \\
\hline $\begin{array}{l}15.214, \mathrm{I}, 13 \\
376\end{array}$ & 10 & 276 & $\begin{array}{r}18 / 1 / 1616 \\
\mathbf{1 6} / \mathbf{1 1} / \mathbf{1 6 1 5}\end{array}$ & $\begin{array}{l}\text { Doctor Juan de Zapata, } \\
\text { Consejo de Inquisición }\end{array}$ & obispado Zamora \\
\hline $\begin{array}{l}15.214, \text { II, } 13 \\
14 / 136\end{array}$ & 10 & $313 v$ & $\begin{array}{l}28 / 3 / 1616 \\
18 / 7 / 1616\end{array}$ & $\begin{array}{l}\text { Licenciado Alonso } \\
\text { Márquez de Prado, } \\
\text { obispo Tortosa }\end{array}$ & $\begin{array}{l}\text { obispado de } \\
\text { Cartagena }\end{array}$ \\
\hline $\begin{array}{l}15.215, \mathrm{I}, \\
11(5) \\
310\end{array}$ & 10 & $326 \mathrm{v}$ & $\begin{array}{l}27 / 4 / 1616 \\
18 / 7 / 1616\end{array}$ & $\begin{array}{l}\text { Licenciado Juan Vigil de } \\
\text { Quiñones, obispo } \\
\text { Valladolid }\end{array}$ & $\begin{array}{l}\text { obispado de } \\
\text { Segovia }\end{array}$ \\
\hline $\begin{array}{l}15.215, \mathrm{I}, 13 \\
(3) \\
357\end{array}$ & 10 & $332-332 v$ & $\begin{array}{r}9 / 5 / 1616 \\
18 / 7 / 1616\end{array}$ & $\begin{array}{l}\text { Licenciado Martín Manso } \\
\text { de Zúñiga, prior } \\
\text { Roncesvalles }\end{array}$ & obispado de Oviedo \\
\hline $\begin{array}{l}15.215, \mathrm{I}, 12 \\
(2) \\
357\end{array}$ & 10 & $364-364 v$ & $\begin{array}{r}11 / 7 / 1616 \\
5 / 9 / 1616\end{array}$ & $\begin{array}{l}\text { Doctor Francisco Sobrino, } \\
\text { canónigo magistral } \\
\text { Valladolid }\end{array}$ & $\begin{array}{l}\text { arzobispado } \\
\text { Valladolid }\end{array}$ \\
\hline $\begin{array}{l}15.215, I, 10 \\
(2) \\
218\end{array}$ & 10 & 365 & $\begin{array}{r}11 / 7 / 1616 \\
5 / 9 / 1616\end{array}$ & $\begin{array}{l}\text { Doctor Juan Llanos de } \\
\text { Valdés, Consejo } \\
\text { Inquisición }\end{array}$ & obispado de León \\
\hline
\end{tabular}




\begin{tabular}{|c|c|c|c|c|c|}
\hline $\begin{array}{l}\text { LegAHN/ } \\
\text { pág. } \\
\text { EUBEL } \\
\text { vol.IV }\end{array}$ & LIBRO & FOLIO & FECHAS & NOMBRE & CARGO \\
\hline \multirow[t]{2}{*}{$\begin{array}{l}15.216, \text { III, } 21 \\
300\end{array}$} & 11 & 58 & $\begin{array}{r}18 / 11 / 1616 \\
\mathbf{5 / 9 / 1 6 1 6}\end{array}$ & $\begin{array}{l}\text { Licenciado Francisco de } \\
\text { Mendoza, Consejo } \\
\text { Inquisición }\end{array}$ & $\begin{array}{l}\text { obispado de } \\
\text { Salamanca }\end{array}$ \\
\hline & 11 & 85 & $20 / 1 / 1617$ & 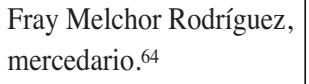 & $\begin{array}{l}\text { obispado auxiliar } \\
\text { de Burgos }\end{array}$ \\
\hline $\begin{array}{l}15.216, \mathrm{I}, 11 \\
103\end{array}$ & 11 & 104 & $\begin{array}{l}10 / 3 / 1617 \\
2 / 10 / 1617\end{array}$ & $\begin{array}{l}\text { Pedro Ruiz Valdivieso, } \\
\text { obispo de Mesina }\end{array}$ & obispado de Orense \\
\hline 15215 III, 27 & 11 & $113-114 v$ & $22 / 3 / 1617$ & $\begin{array}{l}\text { Diego de Peseda, abad S. } \\
\text { Marcos de León. } 65\end{array}$ & obispado aux. León \\
\hline $\begin{array}{l}15.216, \mathrm{I}, 18 \\
198\end{array}$ & 11 & $203 \mathrm{v}+$ & $\begin{array}{l}12 / 8 / 1617 \\
2 / 10 / 1617\end{array}$ & $\begin{array}{l}\text { Doctor Jerónimo de } \\
\text { Herrera, deán catedral } \\
\text { Burgos }\end{array}$ & obispado de Guadix \\
\hline $\begin{array}{l}15.216, \text { II } 21 \\
268\end{array}$ & 11 & $316 v-317$ & $\begin{array}{r}12 / 2 / 1618 \\
9 / 7 / 1618\end{array}$ & $\begin{array}{l}\text { Cristóbal de Lovera, } \\
\text { obispo de Badajoz }\end{array}$ & obispado de Osma \\
\hline $\begin{array}{l}15.216, \text { II } 21 \\
269\end{array}$ & 11 & $317-317 v$ & $\begin{array}{l}12 / 2 / 1618 \\
23 / 8 / 1618\end{array}$ & $\begin{array}{l}\text { Pedro Fernández Zorrilla, } \\
\text { obispo de Mondoñedo }\end{array}$ & $\begin{array}{l}\text { obispado de } \\
\text { Badajoz }\end{array}$ \\
\hline $\begin{array}{l}15.216, \text { II } 21 \\
243\end{array}$ & 11 & $318-318 v$ & $\begin{array}{r}12 / 2 / 1618 \\
6 / 8 / 1618\end{array}$ & $\begin{array}{l}\text { Maestro Fray Rafael Díaz, } \\
\text { Provincial Trinitarios }\end{array}$ & $\begin{array}{l}\text { obispo de } \\
\text { Mondoñedo }\end{array}$ \\
\hline $\begin{array}{l}15216 \text { III,4 } \\
194\end{array}$ & 11 & $390 \mathrm{v}$ & $24 / 5 / 1618$ & $\begin{array}{l}\text { Gaspar de Borja, } \\
\text { embajador en Roma. }{ }^{66}\end{array}$ & obispado de Jaén \\
\hline $\begin{array}{l}15.217, \mathrm{I}, 14 \\
310\end{array}$ & 11 & $391 \mathrm{v}$ & $\begin{array}{r}24 / 5 / 1618 \\
9 / 7 / 1618\end{array}$ & $\begin{array}{l}\text { Alonso Márquez de Prado, } \\
\text { obispo de Cartagena }\end{array}$ & $\begin{array}{l}\text { obispado de } \\
\text { Segovia }\end{array}$ \\
\hline $\begin{array}{l}15.217, \mathrm{I}, 15 \\
136\end{array}$ & 11 & $392 \mathrm{v}$ & $\begin{array}{r}24 / 5 / 1618 \\
9 / 7 / 1618 \\
\end{array}$ & $\begin{array}{l}\text { Fray Antonio de Trexo, } \\
\text { vicario general franciscano }\end{array}$ & $\begin{array}{l}\text { obispado de } \\
\text { Cartagena }\end{array}$ \\
\hline $\begin{array}{l}15217, \text { III, } 48 \\
204\end{array}$ & 12 & 138 & $17 / 12 / 1619$ & $\begin{array}{l}\text { Ldo Juan Portocarrero } \\
\text { abad. Coleg. Villafranca. }{ }^{67}\end{array}$ & $\begin{array}{l}\text { obispado auxiliar } \\
\text { de Sevilla }\end{array}$ \\
\hline 15216,III, 4 & 12 & $188-188 v$ & 2/5/1619 & $\begin{array}{l}\text { Licenciado Diego de } \\
\text { Pereda }^{68}\end{array}$ & $\begin{array}{l}\text { obispado órdenes } \\
\text { militares }\end{array}$ \\
\hline
\end{tabular}

${ }^{64}$ No aparece citado en Eubel-Gauchat.

${ }^{65}$ No aparece citado en Eubel-Gauchat.

${ }^{66}$ Roma nombró a Baltasar Moscoso y Sandoval el 29/4/1619.

${ }^{67}$ No aparece citado en Eubel-Gauchat.

${ }^{68}$ No aparece citado en Eubel-Gauchat.

Hispania Sacra, LX

122, julio-diciembre 2008, 703-733, ISSN: 0018-215-X 


\begin{tabular}{|c|c|c|c|c|c|}
\hline $\begin{array}{l}\text { LegAHN/ } \\
\text { pág. } \\
\text { EUBEL } \\
\text { vol.IV }\end{array}$ & LIBRO & FOLIO & FECHAS & NOMBRE & CARGO \\
\hline $\begin{array}{l}15.218, \mathrm{I}, 6 \\
357\end{array}$ & 12 & $194 \mathrm{v}$ & $\begin{array}{l}19 / 2 / 1619 \\
29 / 7 / 1619\end{array}$ & $\begin{array}{l}\text { Licenciado Enrique } \\
\text { Pimentel, Consejo } \\
\text { Inquisición }\end{array}$ & $\begin{array}{l}\text { arzobispado de } \\
\text { Valladolid }\end{array}$ \\
\hline 339 & 12 & $310 v-328 v$ & $\begin{array}{l}3 / 5 / 1620 \\
\mathbf{1 / 3 / 1 6 2 0}\end{array}$ & $\begin{array}{l}\text { Infante Don Fernando de } \\
\text { Austria }\end{array}$ & $\begin{array}{l}\text { arzobispado de } \\
\text { Toledo }\end{array}$ \\
\hline $\begin{array}{l}15.218, \text { II, } 11 \\
198\end{array}$ & 12 & $338 v-339$ & $\begin{array}{l}1 / 6 / 1620 \\
6 / 4 / 1620\end{array}$ & $\begin{array}{l}\text { Maestro Fray Plácido de } \\
\text { los Santos predicador real }\end{array}$ & $\begin{array}{l}\text { Obispo de Guadix } \\
\text { (Granada) }\end{array}$ \\
\hline $\begin{array}{l}15.219, \mathrm{I}, 12 \\
271\end{array}$ & 12 & 344 & $\begin{array}{l}14 / 6 / 1620 \\
17 / 5 / 1621\end{array}$ & $\begin{array}{l}\text { Francisco de Mendoza, } \\
\text { obispo de Salamanca }\end{array}$ & $\begin{array}{l}\text { obispado de } \\
\text { Pamplona }\end{array}$ \\
\hline $\begin{array}{l}15.219, \text { II, } 11 \\
300\end{array}$ & 13 & $3 v$ & $\begin{array}{l}26 / 9 / 1620 \\
17 / 5 / 1621\end{array}$ & $\begin{array}{l}\text { Doctor Agustín } \\
\text { Corrionero, obispo de } \\
\text { Canaria }\end{array}$ & $\begin{array}{l}\text { obispado de } \\
\text { Salamanca }\end{array}$ \\
\hline $\begin{array}{l}15.219, \text { II, } 12 \\
196\end{array}$ & 13 & $7 v$ & $\begin{array}{r}8 / 10 / 1620 \\
16 / 11 / 1620\end{array}$ & $\begin{array}{l}\text { Galcerán Albanel, } \\
\text { maestro del Príncipe }\end{array}$ & $\begin{array}{l}\text { arzobispado de } \\
\text { Granada }\end{array}$ \\
\hline
\end{tabular}

Sabemos que hubo 107 nombramientos episcopales en la Corona de Castilla durante el reinado de Felipe III: 67 realizados por el rey con terna previa sugerida por la Cámara de Cámara de Castilla y confirmados por el Papa posteriormente. La Santa Sede nombró a 13 obispos antes a la designación regia, es decir, elegidos antes por Roma y posteriormente corroborados por Felipe III.

De los designados para obispos, 45 lo eran ya de otra sede al ser destinados a una nueva diócesis. Se produjo, por tanto, un fenómeno de autoabastecimiento parcial. De los 62 restantes, es decir, de los neo-obispos, conocemos el currículum de 29: 15 eran doctores, 13 licenciados, 1 maestro de órdenes religiosas y de 33 no consta su titulación, cosa que llama la atención ya que el Concilio prescribía que fueran candidatos letrados. De acuerdo con su cursus honorum y ocupación previa al nombramiento, los 62 neo-obispos de los que tenemos información, pueden agruparse así:

A. Canónigos catedralicios y priores colegiatas: 14

1. Luis Fernández de Córdoba, deán de Córdoba

2. Julián García de Valdemoro, canónigo de Alcalá

3. Pedro de Carvajal, deán de Toledo

4. Doctor Lope de Velasco, prior de Roncesvalles 
5. Doctor Jerónimo Ruiz de Camargo, magistral de Ávila

6. Doctor Alonso González, abad de Aguilar de Campoo

7. Doctor Pedro González del Castillo, magistral de Cuenca

8. Doctor Cristóbal Lovera, abad de Lerma

9. Licenciado Martín Manso de Zúñiga, prior de Roncesvalles

10. Doctor Francisco Sobrino, magistral de Valladolid

11. Diego de Peseda, abad de San Marcos de León

12. Licenciado Juan de Portocarrero, abad de Villafranca

13. Pedro de Castro, magistral de Toledo

14. Doctor Jerónimo de Herrera, deán de Burgos

B. Entorno de la Corte: $12^{69}$

15. Doctor Terrones del Cano, capellán y predicador real

16. Hernando Niño de Guevara, Consejo de Estado

17.Fray Juan de Portocarrero, confesor emperatriz

18.Fray Prudencio de Sandoval, OSB, cronista real ${ }^{70}$

19.Doctor Alonso Mejía de Tovar, capellán de las Descalzas Reales de Madrid

20.Doctor Gamarra, cura de Palacio y capellán real

21.Fray Joseph González, OP, confesor del príncipe

22.Fray Diego de Mardones, confesor del rey

23. Infante Don Fernando de Austria ${ }^{71}$

24. Maestro Fray Plácido de los Santos, predicador real

25. Galcerán Albanel, maestro del Príncipe

26. Alonso Manrique, residente en esta Corte

C. Órdenes religiosas: 12

27. Fray Mateo de Burgos, Comisario General OF

${ }^{69}$ Algunos incluidos en esta categoría son, a la vez, religiosos, pero se les ha incluido sólo en el epígrafe «Entorno de la Corte» por su ocupación.

${ }^{70}$ En septiembre de 1600, Felipe III otorgó permiso escrito al benedictino Fray Prudencio de Sandoval para examinar los archivos que necesitara a fin de completar la historia de los reyes de Castilla y León.

AHN Consejos Libro 5 fol. 13-13v.

${ }^{71}$ Sobre este hijo de Felipe III, Vid. Quintín ALDEA, El Cardenal Infante Don Fernando o la formación de un Príncipe de España, Madrid, 1999.

Hispania Sacra, LX

122, julio-diciembre 2008, 703-733, ISSN: 0018-215-X 
28. Fray Enrique Enríquez, Provincial OSA

29. Fray Maestro Alonso Enríquez Armendáriz, Mercedario

30. Fray Francisco de Sossa, ex General OF

31. Fray Pedro González de Mendoza, Comisario OF

32. Fray Sebastián de Bricianos OF

33. Fray Francisco de la Cueva OP

34. Fray Melchor Rodríguez, Mercedario

35. Maestro Fray Rafael Díaz, Provincial de los Trinitarios

36. Fray Antonio de Trexo, Vicario general OF

37. Fray Andrés de Casso, Provincial OP

38. Fray Pedro Ponce de León, OP

D. Relacionados con la Inquisición: 12

39. Thomás de Borja, inquisidor de Málaga

40. Juan de Zúñiga, Consejo de Inquisición

41. Doctor Juan Álvarez de Caldás, Consejo de Inquisición

42. Antonio Venegas, ex miembro Consejo de Inquisición

43. Licenciado Juan Vigil de Quiñones, Inquisidor General

44. Felipe de Taxis, Consejo de Inquisición

45. Licenciado Fernando de Acevedo, Consejo de Inquisición

46. Doctor Juan de Zapata, Consejo de Inquisición

47. Doctor Juan Llanos de Valdés, Consejo de Inquisición

48. Licenciado Enrique Pimentel, Consejo de Inquisición

49. Antonio Venegas, Consejo de Inquisición

50. Licenciado Francisco de Mendoza, Consejo de Inquisición

E. Cargos administrativos: 7

51. Licenciado Gómez de Figueroa, rector Universidad Salamanca

52. Andrés Fernández de Córdoba, auditor de la Rota

53. Licenciado Alonso López Gallo, administrador del hospital de Montesdoca

54. Licenciado Pedro de Zamora, Presidente de la Chancillería de Valladolid

55. Doctor Antonio Corrionero, regente Audiencia de Sevilla

56 Gaspar de Borja, embajador en Roma

57. Pablo de Laguna, Presidente del Consejo de Indias 
F. Órdenes militares: 3.

58. Licenciado Alonso Martínez de la Torre, freyle orden de Santiago

59. Licenciado Nicolás Valdés Carriazo, freyle orden de Santiago

60. Licenciado Juan de Cuenca, freyle orden de Santiago

G. Otros: 2

61. Doctor Diego González de Samaniego

62. Licenciado Diego de Pereda.

Se puede concluir, por tanto, que los neo-obispos eran elegidos mayoritariamente entre personas con determinada formación universitaria, experiencia profesional e incluso cercanía a la Corte.

\section{CANDidatos RechaZAdos POR Felipe III}

Exponemos a continuación y manera detallada los casos en los que se desoyeron los consejos de la Cámara de Castilla y se eligió un candidato no incluido en la terna propuesta. Conocemos 25 casos en las diócesis de la Corona de Castilla durante el reinado de Felipe III, un 30\% del total.

En 1599 y para la vacante del obispado de Málaga, el rey rechazó la candidatura de los obispos de Segovia, Cartagena, Osma y Almería, la de Juan de Zúñiga, Comisario General de la Cruzada y Juan de Morillas, Capellán de Su Majestad; eligió a su candidato, Thomás de Borja, canónigo e inquisidor de Málaga. La razón podría ser la cercanía y conocimiento del candidato regio a su futuro destino ${ }^{72}$.

En 1600 se prefirió la candidatura de Fr. Mateo de Burgos OFM, confesor de la Reina, a los obispos de León, Cádiz, Almería y Guadix, cuyas rentas iban a incrementarse con su nombramiento ${ }^{73}$. La razón pudo ser el que el rey lo conocía personalmente.

En 1602 fue nombrado obispo de Badajoz Andrés Fernández de Córdoba, auditor de la Rota. Fue preferido a seis candidatos propuestos por la Cámara de Castilla, todos ellos doctores. Los candidatos eran los obispos de Lugo y Guadix, otros dos apoyados por los Cardenales Quiroga y de Sevilla y un canónigo de Toledo. El rey rechazó a los recomendados y prefirió a una persona con buena preparación jurídica y que vivía en la Corte ${ }^{74}$.

${ }^{72}$ Cfr. AHN Consejos L.15199,II, 22.

${ }^{73}$ Cfr. AHN Consejos L.15.200, I, 7.

${ }^{74}$ Cfr. AHN Consejos L. 15.202, I, 10.

Hispania Sacra, LX

122, julio-diciembre 2008, 703-733, ISSN: 0018-215-X 
Gómez de Figueroa, rector de la Universidad de Salamanca, fue nombrado en 1602 obispo de Cádiz, quedando fuera tres candidatos de la Cámara de Castilla: un capellán real, un hermano del Marques de Cañete y un apadrinado del Cardenal Quiroga. Parece que este nombramiento fue realizado primero por el Papa y corroborado por Felipe III ${ }^{75}$.

En 1602 la Cámara de Castilla propuso al rey seis candidatos para elegir al futuro obispo de Almería. Felipe III rechazó a todos y designó al franciscano Fray Juan de Portocarrero, confesor de la emperatriz. Es posible que la elección tuviera que ver con la cercanía del candidato a la Corte ${ }^{76}$.

Para el obispado de León, la Cámara de Castilla propuso al rey a los obispos de Mondoñedo, Guadix y Barcelona, al hermano del Marqués de Cañete y otro apoyado por el Conde de Nieva. Felipe III desoyó las recomendaciones y se decantó por Fray Andrés de Casso, Provincial Dominico, con experiencia de gobierno en su orden ${ }^{77}$.

Luis Fernández de Córdoba, antiguo deán de la catedral de Córdoba, fue el candidato seleccionado para la sede de Salamanca después de rechazar a los obispos de Mondoñedo y Barcelona, a otros dos, recomendados del Cardenal Quiroga y del Conde de Nieva, y al deán de Toledo ${ }^{78}$. Felipe III volvió a hacer lo mismo rechazando a cuatro obispos y al hermano del Marqués de Cañete para Osma. Nombró a Fray Enrique Enríquez, Provincial Agustino ${ }^{79}$.

Maximiliano de Austria, obispo de Segovia, fue nombrado arzobispo de Santiago de Compostela contra la voluntad de la Cámara de Castilla que propuso al arzobispo de Granada y a los obispos de Jaén, Burgos y Canaria ${ }^{80}$.

Nombró en 1605, apartándose del dictamen de la Cámara de Castilla, obispo de Sigüenza a Fray Mateo de Burgos, obispo de Pamplona y antiguo confesor de la Reina. Parece que la Santa Sede lo escogió rechazando a los obispos de Zamora, Canaria, Osma y Coria, al deán de Toledo y a un miembro de la General Inquisición. El rey aprobó la elección ${ }^{81}$.

En 1606, Felipe III nombró a su confesor Diego de Mardones obispo de Córdoba, excluyendo a los obispos de Osma, Zamora, Palencia, Pamplona y al deán de Toledo. El electo era persona de su confianza y de su entorno ${ }^{82}$.

\footnotetext{
75 Cfr. AHN Consejos L. 15202, I, 13.

76 Cfr. AHN Consejos L. 15.202,I, 24(2).

77 Cfr. AHN Consejos L. 15.202, II, 2(3).

78 Cfr. AHN Consejos L. 15.202, II, 2(3).

${ }^{79}$ Cfr. AHN Consejos L. 15.202, II,2(3).

${ }^{80}$ Cfr. AHN Consejos L.15.202, II, 3(2).

${ }^{81}$ Cfr. AHN Consejos L. 15.205 II, 3(12).

${ }^{82}$ Cfr. AHN Consejos L. 15.206, II, 3.
} 
En 1609, la Cámara de Castilla propuso al monarca a tres candidatos para ocupar la sede episcopal de Ciudad Rodrigo: el abad de la Colegiata de Alfaro, un canónigo magistral de Toledo y un capellán de Su Majestad. Felipe III escogió al Doctor Sobrino, magistral de Valladolid al que posiblemente conociera durante los años que la Corte permaneció en la ciudad ${ }^{83}$.

En 1611, Felipe III confirmó como obispo de Orense al franciscano Fray Sebastián de Bricianos, designado por la Santa Sede. Se apartó de la propuesta de la Cámara de Castilla, que postuló a Miguel de Ayala, Maestro de Artes de Alcalá, Francisco Gasca, Abad de San Isidoro de León y al benedictino Fray Plácido de los Santos ${ }^{84}$.

Antonio Venegas, obispo de Pamplona, fue trasladado en 1611 a la sede de Sigüenza por voluntad de la Santa Sede. Quedaron fuera los obispos de Segovia, Cartagena y Salamanca. El rey le aprobó ${ }^{85}$. Ese mismo año Nicolás Valdés de Carriazo, obispo de Canaria y antiguo capellán de Su Majestad, fue nombrado por el rey obispo de Guadix, excluyendo a otros capellanes y predicadores del rey. La elección se debió, como es evidente, a la experiencia pastoral del candidato regio respecto a los de la Cámara de Castilla ${ }^{86}$. Fue trasladado a Badajoz también en 1611 Fray Pedro Ponce de León, hasta entonces obispo de Zamora. Fue preferido al obispo de Valladolid y a dos canónigos de Cuenca ${ }^{87}$.

En 1612, fue nombrado obispo de Tuy, Juan García de Valdemoro, hasta entonces de Lugo. Fue el candidato regio seleccionado quizá por la cercanía geográfica de la nueva sede ${ }^{88}$.

En 1615 se apartó el Rey de las propuestas de la Cámara de Castilla en varios nombramientos Para el obispado de Badajoz el Doctor Cristóbal de Lovera, abad de la Colegiata de Lerma. Los candidatos de la Cámara de Castilla fueron los obispos de Jaca y Mondoñedo, dos inquisidores y un oidor de la Real Chancillería. Es posible que el candidato designado llegara a conocimiento del rey a través de Duque de Lerma ${ }^{89}$. Los mismos candidatos, ahora para la sede de Cartagena, fueron otra vez rechazados. Se designó al Dr. Gamarra, cura de Palacio y capellán real ${ }^{90}$. El rey designó al obispo de Salamanca y al Segovia: en el primer caso, corroboró la decisión vaticana de designar a Fray Diego Ordóñez,

${ }^{83}$ Cfr. AHN Consejos L. 1208, I, 17.

${ }^{84}$ Cfr. AHN Consejos L. 15210 I, 6.

${ }^{85}$ Cfr. AHN Consejos L. 15210, I, 7(1).

${ }^{86}$ Cfr. AHN Consejos L. 15210, I, 8(1).

${ }^{87}$ Cfr. AHN Consejos L. 15210,II 4(1).

${ }^{88}$ Cfr. AHN Consejos L. 15211, I, 9.

${ }^{89}$ Cfr. AHN Consejos L. 15.213, II, 13.

${ }^{90} \mathrm{Cfr}$. AHN Consejos L. 15.213, II, 13. Fue nombrado por el rey ese mismo año obispo de Astorga, preferido a otros candidatos.

Hispania Sacra, LX

122, julio-diciembre 2008, 703-733, ISSN: 0018-215-X 
obispo de Jaca, ex General Franciscano, candidato en su momento apoyado por la Infanta Margarita. Fueron rechazados notorios representantes del Consejo Real, de Inquisición e Indias ${ }^{91}$. Para Segovia, Juan Vigil de Quiñones, obispo de Valladolid, quedando fuera los obispos de Coria, Orense, Ciudad Rodrigo y Palencia ${ }^{92}$. Para Oviedo; fue nombrado Martín Manso de Zúñiga, prior de Roncesvalles, preferido al deán de Burgos, a un magistral de Zamora y a un capellán de Su Majestad ${ }^{93}$.

Juan Zapata, miembro del Consejo de Inquisición, fue nombrado por la Santa Sede obispo de Zamora, cargo confirmado por el rey, desbancando a los obispos de León, Valladolid y Astorga y a Rodrigo de Castro, también Consejero de Inquisición y al Dr. Gamarra, Cura de Palacio ${ }^{94}$. Alonso Mejía de Tovar, hasta entonces obispo de Mondoñedo, fue preferido para la sede de Astorga a dos Consejeros reales, el obispo de Orense y dos canónigos magistrales ${ }^{95}$.

Francisco Gamarra, a la sazón obispo de Cartagena y antiguo Cura de Palacio, fue elegido en 1616 obispo de Ávila, para donde eran candidatos los obispos de Tuy y Ciudad Rodrigo, tres canónigos magistrales de Toledo, Zamora y Córdoba y el deán de Burgos ${ }^{96}$. El mismo año, Alonso Márquez de Prado, obispo de Tortosa, fue designado para la sede de Cartagena, descartando a los mismos candidatos que en el caso del Dr. Gamarra97. En 1618 quedó nuevamente vacante la sede de Cartagena y el rey contradijo de nuevo a la Cámara de Castilla eligiendo a Fray Antonio de Trejo, Vicario General Franciscano, tras excluir a los obispos de Zamora, Astorga y Ciudad Rodrigo ${ }^{98}$.

Por último, en 1620, Galcerán Ábranel, Maestro del Príncipe, fue preferido por el rey para el arzobispado de Granada, tras descartar a candidatos como los obispos de Sigüenza, Coria, Málaga y Badajoz, y al presidente de la Real Chancillería de Granada ${ }^{99}$.

En resumen, durante el reinado de Felipe III y sobre un total de 67 ternas documentadas, se realizaron 25 nombramientos episcopales contra las sugerencias de la Cámara de Castilla. Bastantes nombramientos se concentraron en los años 1602 y 1615 . Nueve de los elegidos eran ya obispos, 5 confesores o capellanes de la Corte, 4 religiosos, 3 canónigos o abades y 2 auditores o rectores.

\footnotetext{
91 Cfr. AHN Consejos L. 15.214, I, 14.

${ }^{92}$ Cfr. AHN Consejos L. 15.215, I , 11.

93 Cfr. AHN Consejos L. 15.215, I, 13.

${ }^{94}$ Cfr. AHN Consejos L. 15.214, I, 13.

95 Cfr. AHN Consejos L. 15.214, II, 3.

96 Cfr. AHN Consejos L. 15.214, II, 1314.

${ }^{97}$ Cfr. AHN Consejos L. 15.214, II, 1314.

98 Cfr. AHN Consejos L. 15.217, I, 15.

${ }^{99}$ Cfr. AHN Consejos L. 15.219, II, 12.
} 
Aportación de la Nunciatura de la Santa Sede en España

Además de estudiar los nombramientos episcopales en los denominados $\mathrm{Li}$ bros de Iglesia y en la Sección de Consejos del AHN, interesa también consultar la documentación disponible de la Nunciatura de la Santa Sede en España durante el reinado de Felipe III.

Los datos han sido puestos a disposición de los investigadores por J. Olarra y M.J. Larramendi, en siete volúmenes editados por el Instituto de Estudios Eclesiásticos de Roma entre 1962 y 1967100.

Entre 1598 y 1621 fueron legados pontificios en Madrid: Nuncio Caetani 1599-febrero 1600, Ginnasio febrero 1600-junio 1604, Millino desde junio 1604-mayo 1607, Caraffa mayo 1607-diciembre 1611, Caetani enero 1612agosto 1618 y Cennini desde agosto 1618.

Dado que los nombramientos episcopales eran una atribución regia, resulta sugestivo averiguar en qué grado la documentación de la Nunciatura se hace eco de estas elecciones eclesiásticas ${ }^{101}$.

La designación del ex obispo de Jaén, Bernardo Rojas de Sandoval, tío del Duque de Lerma, como primado de España a finales de marzo de 1599 aparece en la documentación entre la legación vaticana y Roma. Quince días más tarde del nombramiento, el Cardenal Aldobrandini escribía al Nuncio Caetani sobre el particular y el 28 de mayo, el electo agradecía además al Papa el capelo cardenalicio ${ }^{102}$. A principios de junio, el Duque de Lerma escribió al Cardenal Aldobrandini sobre la pensión de 3000 ducados sobre Toledo a favor del nuevo Cardenal ${ }^{103}$. Meses más tarde, el Nuncio Caetani hacía relación escrita al Cardenal Aldobrandini sobre la fiesta celebrada en la ciudad con motivo del cardenalato de Bernardo Rojas de Sandoval ${ }^{104}$.

El siguiente documento que aparece reseñado en la Nunciatura es una carta de Tomás de Borja, inquisidor de Málaga, nombrado obispo esta diócesis por el rey el 3 de diciembre de 1599. Sólo un día más tarde, consta que envió una misiva a Roma a través del Nuncio ${ }^{105}$.

100 Vid. J. OlarRa-M. L. LaRRAmEndi, Correspondencia entre la Nunciatura en España y la Santa Sede (1598-1621), Roma, 1962-1967, vols. I-VII.

${ }^{101}$ En la documentación aparece con mucha frecuencia la recomendación de personas, la concesión de oratorios privados y el envío del vino siciliano para el Colegio cardenalicio.

${ }^{102}$ ASV Nunciatura en España 327. 60/61 J. OLARRA-M. L. LARRAMENDI, o.c. vol. I p. 64 y 73.

103 Ibidem ASV Nunciatura en España 52.435 vol. I p. 77.

${ }^{104}$ Ibidem ASV Nunciatura en España 50.527vol. I p. 130. Se le entregó el capelo el 13 de marzo de 1600 en Toledo en presencia de los reyes.

105 Ibidem ASV Nunciatura en España 327.128 vol. I p. 114 (4-12-1599).

Hispania Sacra, LX

122, julio-diciembre 2008, 703-733, ISSN: 0018-215-X 
Según aparece en los Libros de Iglesia, Antonio Zapata, ex obispo de Pamplona fue designado arzobispo de Burgos en octubre de 1600 y la sede navarra fue ocupada por Mateo de Burgos, Comisario General de los Franciscanos, confesor electo de la reina Margarita de Austria. Estos nombramientos fueron comunicados por el Nuncio Ginnasio al Cardenal Aldobrandini a título informativo ${ }^{106}$. El mismo Nuncio daba cuenta ese otoño sobre los candidatos para el arzobispado de Sevilla. Eran Hernando Niño de Guevara, del Consejo de Estado, Tomás de Borja, obispo de Málaga y Maximiliano de Austria, obispo de Segovia ${ }^{107}$. Resultó elegido el primero en abril del año siguiente ${ }^{108}$.

Hay que esperar unos meses para encontrar alguna otra referencia a los nombramientos episcopales. El Nuncio Ginnasio informó en 1601 al Cardenal Ascanio sobre la provisión de las sedes de Cuenca, con Andrés Pacheco, ex obispo de Segovia, y de la esta con Maximiliano de Austria, ex obispo de Cádiz ${ }^{109}$.

En verano de 1602 el Nuncio Ginnasio anunciaba al Cardenal Aldobrandini la muerte del arzobispo de Santiago. La vacante sería cubierta por el arzobispo de Granada ${ }^{110}$. No lo fue. Se nombró a Maximiliano de Austria, obispo de Segovia ${ }^{111}$. A finales de año en el Nuncio Ginnasio indicaba al Cardenal Aldobrandini que el arzobispo de Burgos sería trasladado a Córdoba y el de Córdoba a Zaragoza. Volvió a equivocarse el nuncio ${ }^{112}$.

Hasta 1612 no se registran más referencias a nombramientos episcopales ${ }^{113}$. En noviembre de ese año la Secretaría de Estado envió un mensaje al Nuncio Caetani informándole del cargo de conciencia del confesor del rey por el traslado frecuente de los obispos de una sede a otra ${ }^{114}$.

En 1613 se alude a los derechos de la Cámara Apostólica con motivo de las vacantes de Burgos, Calahorra y Cádiz, según informa el Nuncio Caetani ${ }^{115}$. En

106 Cfr. AHN Consejos Libro 5 fols. 37-38v y ASV Nunciatura en España 53.45 J. OlARRA-M. L. LARRAMENDI o.c. vol. I p. 137.

${ }^{107}$ Cfr. ASV Nunciatura en España Ibidem 53 223/234 vol. I p. 180.

108 Cfr. AHN Consejos Libro 5 fol. 62v.

109 Cfr. ASV Nunciatura en España J.OlarRA-M.L.LARRAMENDI o.c. 54. 51/52 vol. I p. 203

${ }^{110}$ Cfr. ASV Nunciatura en España Ibidem 55.339 vol. II p. 76.

${ }^{111}$ Cfr. AHN Consejos Libro 5 fols. 286v-290.

112 Cfr. ASV Nunciatura en España J. OlarRA-M. L. LARRAMENDI o.c 55.432. vol. II pp. 105-106.

${ }^{113}$ Hay sin embargo referencias de interés para la historia de la Iglesia en estos años; por ejemplo, el hecho de que los Nuncios apostólicos en España fueran creados cardenales al terminar su mandato, al menos desde el Nuncio Millino. Cfr. ASV Nunciatura en España Ibidem 333. 287 vol. III p. 63 y 334. 124 p. 114.

${ }^{114}$ Cfr. ASV Nunciatura en España 337.281 vol. IV p. 235. El confesor real era el P. Luis de Aliaga y efectivamente su opinión parece que se tenía en cuenta en las elecciones episcopales. Vid. José NAVARRO LATORRE, Aproximación a Fray Luis de Aliaga, confesor de Felipe III e Inquisidor General de España,Zaragoza, 1981.

115 Cfr. ASV Nunciatura en España 338.402 J. OlarRa-M. L. LARRAMENDI vol. V, p. 31. 
1614 el Nuncio envió a sus superiores datos sobre los nombramientos del obispo de Salamanca destinado a Málaga y el de Jaén, a Sigüenza'116. En 1615, la Secretaría vaticana comunicaba al Nuncio el levantamiento de las censuras por las diferencias jurisdiccionales entre el Cardenal Borromeo y los ministros del rey ${ }^{117}$. Pocas fechas más tarde, recibía instrucciones sobre su conducta para las vacantes episcopales ${ }^{118}$.

La última referencia a nombramientos episcopales en la correspondencia de la Nunciatura data de abril de 1618. Caetani informa al Cardenal Borghese de la designación del Doctor Valdivieso para la sede de Valladolid, del obispo de Cartagena, para Segovia, del de Astorga, para Cartagena y del Vicegeneral de los Franciscanos para Astorga ${ }^{119}$. Solo acertó, según los datos que proporcionan los Libros de Iglesia, con el obispo de Cartagena destinado a Segovia ${ }^{120}$.

La información sobre los nombramientos episcopales de Felipe III en los documentos de la Nunciatura en Madrid no supone un esclarecimiento significativo sobre los datos disponibles del Archivo Histórico Nacional y concretamente no aportan noticias sobre los 13 casos en los que la fecha de nombramiento de Roma es anterior al de Felipe III.

\section{CONCLUSIONES}

Para finalizar, podemos llegar a algunas conclusiones, si bien se ha de tener en cuenta que este artículo pretende sólo ser una aproximación a los nombramientos episcopales en la Corona de Castilla bajo el reinado de Felipe III.

Felipe III solicitó candidatos adecuados a los obispos y cabildos; su intención era que los nombrados tuvieran ciencia y virtud, aunque no siempre consta su adecuado nivel académico. El rey otorgó también cargos eclesiásticos como premio a los años de servicio a la Corona.

Durante el reinado se realizaron 107 nombramientos episcopales, renovando el total de las 37 sedes episcopales de la Corona de Castilla. De esos 107 nombramientos, ha llegado hasta nosotros la terna de 67 nombramientos episcopales; 40 designados carecen de ella; quizá fueron nombrados directamente por el

${ }^{116}$ Cfr. ASV Nunciatura en España 60B.545 Ibidem vol. V, p. 234.

117 Cfr. ASV Nunciatura en España 339.258/259 Ibidem vol. VI, p. 42.

118 Cfr. ASV Nunciatura en España 340.157/158 Ibidem vol. VI, p. 144. Estas indicaciones le fueron útiles según consta en correspondencia de 1617; Cfr. ASV Nunciatura en España 60E.411Ibidem vol. VI, p. 219.

${ }^{119}$ Cfr. ASV Nunciatura en España 60F. 146 Ibidem vol. VI p. 33.

${ }^{120}$ El obispo de Valladolid no fue el Doctor Valdivieso (designado obispo de Orense) sino Enrique Pimentel, del Consejo de Inquisición y el Vicario de los Franciscanos fue obispo de Cartagena. Vid. AHN Consejos Libros 10-12.

Hispania Sacra, LX

122, julio-diciembre 2008, 703-733, ISSN: 0018-215-X 
rey, según Barrio Gozalo al menos el 10\% de los casos, o bien contando en ocasiones con el consejo de su confesor, teniendo en cuenta los candidatos que periódicamente enviaban los obispos al monarca.

Respecto a estas 67 ternas, el rey desoyó la propuesta de la Cámara de Castilla en el $30 \%$ de los casos, designado a otro candidato, es decir, en una tercera parte de los casos, una proporción importante. Hubo 25 nombramientos episcopales contra las sugerencias de la Cámara de Castilla, sobre un total de 67 ternas documentadas. Los elegidos fueron 9 siendo ya obispos, 5 confesores o capellanes de la Corte, 4 religiosos, 3 canónigos o abades y 2 auditores o rectores.

De los 107 designados, 45 eran ya obispos, los 62 restantes fueron: 12 canónigos catedralicios, 14 eran priores de colegiatas, 12 personas del entorno de la Corte, otros 12, miembros de Órdenes o Congregaciones religiosas, 7 individuos vinculados al Tribunal de Inquisición, 3 personas con cargos administrativos, 3 miembros de Órdenes Militares y 2 no están incluidos en estas categorías.

De los 62 nuevos designados, hay 29 con curriculum conocido: 15 eran doctores, 13 licenciados y 1 maestro religioso; del resto (33) se desconoce su nivel académico.

Del total de los 107 obispos elegidos, atendiendo a las fechas, consta que en el caso de 13 de ellos, la Santa Sede procedió a su nombramiento antes de que fueran corroborados por el rey.

La correspondencia entre el Nuncio de la Santa Sede en España y Roma no aporta datos significativos sobre los nombramientos episcopales durante el reinado de Felipe III y concretamente no da noticia sobre los 13 nombramientos episcopales realizados por Roma en fecha previa a la designación de Felipe III.

De momento, no es posible probar documentalmente la influencia de los confesores regios en los nombramientos episcopales durante el reinado de Felipe III. En las fuentes consultadas parece no haber rastro escrito de su intervención en los nombramientos episcopales. 